\title{
NOUVELLES RECHERCHES DE ZYMOLOGIE MÉDICALE
}

\author{
Par Maurice LANGERON et Paul GUERRA
}

\section{DEUXIEME PARTIE}

\author{
Études moNographiques SUR LES MYCotoruloIdéES \\ (suite)
}

Le genre Candida Benkhout 1923

(suite)

CANDIDA Berkhout 1923, p. 41

1842 \& Sporotrichum sp. ? Gruby 1842, p. 634.

1853 « Oidium Link 1809 * Ch. Robin 1853, p. 488.

1866 * Stemphylium Wallroth 1833 , Hallier 1866, p. 86.

1868 Syringospora Quinquaud 1868, p. 290.

1877 \& Saccharomyces Meyen 1837 ; Reess 1877 , p. 190.

* Mycoderma Persoon 1822 ; Grawitz, 1877, p. 209.

1885 Monilia Plaut 1885, non Bonorden.

1890 \& Dematium Persoon 1797 , Laurent 1890, p. 14.

1896 * Empusa Cohn 1855 * Heim 1896.

1898 \& Endomyces Reess 1870 , Vuillemin 1898, p. 630 et 1899, p. 43.

1901 * Cryptococcus Kützing 1833 , Vuillemin 1901, p. 752.

1909 Parendomyces Queyrat et Laroche 1909, p. 111.

Parasaccharomyces de Beurmann et Gougerot 1909, p. 502.

Zymonema de Beurmann et Gougerot 1909, p. 503.

(Pour ces trois genres, voir plus haut p. 173-178).

1910 Pseudomonilia Geiger 1910, p. 97.

Trichosporum Du Bois 1910, p. 447.

1916 Pseudomycoderma Will 1916, p. 278.

Mycotorula Will 1916, p. 226.

1911 Enantiothamnus Pinoy 1911, p. 592 (in Brault et Masselot 1911, p. 592). (Voir plus loin : Remarques critiques).

\& Monilia Gmelin 1791 , Vuillemin 1911, p. 137 (groupe Gmelin).

1924 Blastodendrion Ota 1924, p. 216.

Myceloblastanon Ota 1924, p. 216.

Axsales de Panasitoloat, T, XVI, $\hat{\mathbf{x}}^{\circ}$ 5. - $1^{\text {er }}$ septembre 1938. 
1930 Schizoblastosporion Ciferri 1930 , p. 446.

1931 Endomycopsis Stelling Dekker 1931, p. 264. (Voir plus loin : Remarques critiques).

1932 Mycotoruloides Langeron et Talice 1932, p. 48.

Mycocandida Langeron et Talice 1932, p. 56.

Geotrichoides Langeron et Talice 1932, p. 62.

1935 * Guilliermondella Nadson et Krassilnikoff 1928 ; C. W. Dodge 1935 , p. 136.

Actonia C. W. Dodge 1935 , p. 145. (Potr ces deux genres voir plus loin : Remarques critiques).

Castellania C. W. Dodge 1935, p. 246. (Voir plus haut, p. 174).

\& Trichosporum Behrend 1890 * Ciferri et Redaelli 1935. p. 19 et 58.

Champignons levuriformes dont la forme parfaite ascosporée est inconnue et dont la forme imparfaite est constituée par un pseudomycélium portant des verticilles réguliers de blastospores.

1. Eléments morphologiques. - Blastospores ou éléments bourgeonnants, susceptibles de se multiplier indéfiniment sous cette forme et de former des amas difTus (colonies crémeuses).

Pseudomycélium formé de blastospores attachées bout à bout, plus ou moins allongées et constituant des filaments parfois très longs.

Verticilles de blastospores développés à l'apex des articles du pseudo-mycélium : ces verticilles sont d'abord simples, sous la forme de petites couronnes régulièrement espacées à l'apex des articles, puis se transforment d'abord en glomérules et finalement en véritables manchons entourant le filament axial, par suite de la prolifération des blastospores par bourgeonnement.

Pseudo-conidies parfaitement distinctes des blastospores parce qu'elles naissent toujours lateralement sur les articles du pseudomycélium et jamais apicalement comme les blastospores. Elles sont souvent portées par un denticule et peuvent être associées en chaînettes plus ou moins allongées ou former un manchon (d'une seule couche de spores) autour du filament axial. Ces éléments sont surtout développés chez les Candida du groupe tropicalis.

Les pseudo-conidies ont été vues et figurées par Vuillemin (1899, pl. CXC, fig. 11) chez C. albicans. Cette figure est reproduite dans tous les ouvrages classiques.

Chlamydospores, éléments caractéristiques des Candida du groupe albicans. Véritables kystes de conservation, naissant d'une cellule spécialisée, la protochlamydospore qui est le siège d'une intense condensation protoplasmique. 
2. Eléments physiologiques. - Zymogramme positif ou négatif pour des sucres fermentescibles déterminés, donnant ainsi une formule constante, caractéristique pour chaque groupe ; il y a, en outre, un groupe azymatique, à zymogramme négatif pour tous les sucres.

Auxanogramme des sucres non superposable au zymogramme, en général plus étendu et moins caractéristique.

Auxanogramme de l'azote, le principal élément différentiel étant l'urée.

L'énumération de ces éléments morphologiques et physiologiques remplace la diagnose classique et permet de mieux caractériser ces champignons.

3. Éléments systématiques. - Ces éléments peuvent être répartis en 7 groupes, basés sur le zymogramme comme nons l'avons indiqué plus haut (p. 81-82). Ces groupes portent le nom de l'espèce dont le zymogramme a servi de type :

1 , albicans ; 2 , tropicalis ; 3 , pseudotropicalis ; 4 , guilliermondi ; 5 , krusei ; 6, brumpti; 7 , groupe azymatique.

\section{GROUPE ALBICANS}

1. Eléments morphologiques. - A. Filamentisation du type Mycotorula ou Mycotoruloỉdes, c'est-à-dire pseudo-mycélium portant des verticilles de blasfospores, formant des glomérules régulièrement espacés. La filamentisation est plus ou moins développée suivant les souches.

B. Blastospores arrondies ou ovalaires, généralement monomorphes.

C. Chlamydospores. - Elément morphologique absolument caractéristique de ce groupe, naissant le plus souvent aux dépens d'une cellule piriforme spécialisée, la protochlamydospore.

D. Pseudo-conidies plus ou moins abondantes dans presque toutes les souches.

2. Zymogramme (1) de levures zymato-osidasiques maltasiques, positif pour : glycose et maltose.

3. Auxanogramme des sucres (1) négatif pour le maltose et le raffinose.

(1) Ces earactérístiques biologiques essentielles ne sont données que pour les sucres et les corps azotés les plus importants pour définir les groupes. On trouvera, pour chaque espéce, les zymogrammes et auxanogrammes complets. 
4. Auxanogramme de l'azote (1) positif pour l'urée, mais zone d'assimilation tardive, très étendue et seulement opalescente.

5. Eléments systématiques. - Deux espèces :

C. albicans (Ch. Robin 1853);

C. triadis (Langeron et Talice 1932).

CANDIDA ALBICANS (Ch. Robin 1853, p. 488) Berkhout 1923, p. 44

1842 \& Sporotrichum sp. \$ Gruby 1842 , p. 634.

1853 \& Oidium albicans * Ch. Robin 1853, p. 488.

1866 \& Stemphylium polymorpham Bonorden 1851 . Hallier, 1866, p. 86.

(Voir plus loin : Remarques critiques).

1868 Syringospora robini Quinquaud 1868, p. 290.

1877 Saccharomyces albicans Reess 1877, p. 190.

\& Mycoderma vini s Grawitz 1877, p. 209.

1885 Monilia candida Plaut 1885 noz Bonorden.

1890 \& Dematium albicans, Laurent 1890, p. 14. (Voir plus loin : Remarques critiques).

Monilia albicans (Robin 1853) Zopf, 1890, p. 478.

1897 Endomyces albicans Johan-Olsen 1897, p. 276, non Vuillemin.

1898 Endomyces albicans Vuillemin 1898, p. 630.

1909 Parendomyces albus Queyrat et Laroche 1909, p. 111 (chlamydospores).

1910 \& Trichosporum glycophile \& Du Bois 1910, p. 447. (Voir plus loin : Remarques critiques).

1912 Endomyces pinoyi (2) Castellani 1912, p. 15.

Endomyces frecalis Castellani 1912, p. 1208.

Parasaccharomyces harteri Verdun 1913, p. 731 (chlamydospores). Endomyces vuillemini Landrieu 1912, p. 106.

1913 ? Monilia decolorans Castellani et Low 1913, p. 33.

M. pinoyi (2) Castellani et Chalmers 1913, p. 826.

1916 M. metchniko $/ i$ Castellani 1916, p. 149.

1917 M. psilosis (2) Ashford 1917, p. 157.

1918 Parasaccharomyces albicans F. de Mello et Fernandes 1918, p. 271. Endomyces pulmonalis Senez 1918, p. 58 (chlamydospores d'après Pollacei et Nannizzi 1925, $\mathrm{n}^{\circ} 34$ ).

1919 Monilia nabarrot Castellani et Chalmers 1919, p. 1090.

M. pseudolondinensis Castellani et Chalmers 1919, p. 1082.

M. psendolondinotdes Castellani et Chalmers 1919, p. 1082.

M. metalondinensis Castellani et Chalmers 1919, p. 1082.

(1) Ces caractếristiques biologiques essentielles ne sont données que pour les sucres et les corps azotês les plus importants pour définir les grovpes. OH trouvera, pour chaque espèce, les zymogrammes et auxanogrammes complets.

(2) La synonymie pinogi-psilosis = albicans a été admise en 1934 par Shrewsbury (1934, p. 313-354). 
M. pseudometalondinensis Castellani et Chalmers 1919, p. 1082.

M. alba Castellani et Chalmers 1919, p. 1089.

$M$. bethaliensis Pijper in Castellani et Chalmers 1919, p. 1091.

Endomyces tropicalls Acton 1919, p. 591 (chlamydospores).

1921 Monilia pseudoalbicans Neveu-Lemaire 1921, p. 77 (chlamydospores).

Cryplococcus copellii Neveu-Lemaire 1921, p. 79 (chlamydospores). Oidiomyces unguium Frei 1921, p. 404.

1922 Endomyces molardi Salvat et Fontoynont 1922, p. 311 (chlamydospores).

1923 Cryptococcus laryngitidis Sartory, Petges et Claoué (1) 1923, p. 179.

1924 Myceloblastanon (Mycelorhizodes) culaneum Ota 1924, p. 231.

Monilia de Kauffmann-Wolff Ota 1924, p. 234-235 (chlamydospores).

1925. Myceloblastanon favrei Ota 1925, p. 181.

1926 Monilia richmondi Shaw 1926, p. 300.

Blastodendrion intestinale Mattlet 1926, p. 16.

Mycotorula tonsille Carnevale-Ricci 1926, p. 26.

Myceloblastanon gifuense Taniguchi 1926, p. 92.

1927 Monilia bucalis (2) Niño et Puglisi 1927, p. 222 (chlamydospores).

1928 Monilia fioccoi Pollacci et Nannizzi 1928, $\mathrm{n}^{*} 77$ (chlamydospores). Myceloblastanon albicans Ota 1928, p. [5] (chlamydospores).

M. skutetzkyi Ota 1928, p. 126.

1929 Monilia mannitofermentans Castellani 1929, p. 544.

Endomyces albicans Okabe 1929, p. 181, non aliorum.

1930 Monilia periunguealis Niño 1930 , p. 270.

M. vaginalis Mazza et De los Rios 1930, p. 215.

Cryptococeus sp. Negroni 1930, p. 648.

1931 Monilia actoni Vuillemin 1931, p. 84.

M. alvarezsotoi Mazza, Niño, Quintana et Bernasconi, 1931, p. 180. Candida albicans Basgal 1931, p. 49.

Endomycopsis albicans (Vuillemin 1898) Stelling Dekker 1931, p. 231.

1932 Monilia inexorabilis Mazza et Palamedi 1932, p. 424.

Mycotoruloides ovalis Langeron et Talice 1932, p. 49.

Blastodendrion erectum Langeron et Talice 1932, p. 62.

B. pinoyi (Cast. 1912) Langeron et Talice 1932, p. 62.

Mycotorula albicans (Ch. Robin 1853) Langeron et Talice 1932, p. 44.

1933 Blastodendrion oosporoides Zach 1933, p. 102.

Cryptococcus pinoysimilis Castellani 1933, p. 297.

1935 Atelosaccharomyces laryngitidis (Sartory, Petges et Claoué 1923) C. W. Dodge 1935, p. 344.

Zymonema harteri (Verdun 1912) C. W. Dodge 1935, p. 178 (chlamydospores).

(1) Et non \& Claqué s comme l'écrit C. W. Dodge.

(2) \& bucalis * au lieu de buccalis.

Axsales de Pansitolocik, T. XVI, N" 5. - 1er septembre 1938. 
Zymonema molardi (Salvat et Fontoynont 1922) C. W. Dodge 1935. p. 173 .

1935 ? Zymonema album C. W. Dodge, 1935, p. 175 (chlamydospores).

Z. alvarezsotoi (Mazza et Niño 1931) C. W. Dodge 1935, p. 177 (chlamydospores).

Z. albicans (Okabe 1929) C. W. Dodge 1935, p. 174.

Z. bucalis (Niño et Puglisi 1927) C. W. Dodge 1935, p. 176.

Mycoderma pseudoalbicans (Neveu-Lemaire 1921) C. W. Dodge 1935, p. 229.

Guilliermondella vuillemini (Lindau ?) C. W. Dodge 1935, p. 136. Actonia tropicalis (Acton 1919) C. W. Dodge 1935, p. 146.

Parendomyces periunguealis (Niño 1930) C. W. Dodge 1935, p. 239.

P. albus (Queyrat et Laroche 1909) C. W. Dodge 1935, p. 240.

Castellania alba (Cast. et Chalmers 1919) C. W. Dodge 1935, p. 262.

C. copellit (Neveu-Lemaire 1921) C. W. Dodge 1935, p. 252 (chlamydospores).

C. decolorans (Cast. et Low 1913) C. W. Dodge 1935, p. 253.

C. fuecalis (Cast. 1912) C. W. Dodge 1935, p. 254.

C. mannitofermentans (Cast. 1929) C. W. Dodge 1935, p. 255.

C. metalondinensis (Cast. et Chalmers 1919) C. W. Dodge 1935, p. 256.

C. metchniko ff (Cast. 1916) C. W. Dodge 1935, p. 250.

C. nabarroi (Castellani et Chalmers 1919) C. W. Dodge 1935, p. 253.

C. pseudolondinensis (Cast. et Chalmers 1919) C. W. Dodge 1935, p. 255.

C. pseudolondinoides (Cast. et Chalmers 1919) C. W. Dodge, 1935, p. 255.

C. pseudometalondinensis (Cast. et Chalmers 1919) C. W. Dodge 1935 , p. 255.

C. richmondi (Shaw 1926) C. W. Dodge 1935, p. 256.

Parasaccharomyces oosporoides (Zach 1933) C. W. Dodge 1935, p. 266.

P. colardi C. W. Dodge 1935, p. 267 (chlamydospores).

P. intestinale (Mattlet 1926) C. W. Dodge 1935, p. 268.

Syringospora albicans (Ch. Robin 1853) C. W. Dodge 1935, p. 274 (chlamydospores).

S. cutanea C. W. Dodge 1935, p. 278.

?S. hasegawa C. W. Dodge, 1935, p. 282 (chlamydospores).

S. inexorabilis (Mazza et Palamedi 1932) C. W. Dodge 1935, p. 242.

$S$. negroni C. W. Dodge 1935, p. 280 (chlamydospores).

S. psilosis (Ashford 1917) C. W. Dodge 1935, p. 279.

Blastodendrion favrei (Ota 1925) C. W. Dodge 1935, p. 286.

B. cutaneum (Ota 1924) C. W. Dodge 1935, p. 287.

B. gifuense (Taniguchi 1927) C. W. Dodge 1935, p. 288.

Candida bethallensis (Pijper in Cast. et Chalmers 1919) C. W. Dodge 1935 , p. 231. 
C. mycotoruloidea Redaelli et Ciferri 1935, p. 50.

Mycocandida skutetzkyi (Ota 1928) C. W. Dodge 1935, p. 293 (chlamydospores).

\section{Remarques critiques}

Cette synonymie touffue (1) est due à plusieurs causes dont les deux principales sont' l'extrême fréquence de ce champignon chez l'homme et l'absence totale de méthode dans l'étude qui a été faite des diverses souches. Il en est résulté qu'on a cru presque toujours découvrir un champignon nouveau. L'erreur la plus fréquente, qui est à la base de toutes ces fausses déterminations, est qu'on a négligé de purifier la souche avant de l'étudier, d'où toutes ces fermentations fantaisistes qui ont conduit à la création de noms nouveaux. On ne saurait trop insister sur la fréquence et le danger des infections latentes que nous avons décrites plus haut (p. 51). Si l'on veut faire du travail sérieux, toute souche de levure doit passer au moins une fois en Raulin pendant une dizaine de jours, de manière à détruire sûrement toutes les bactéries. Cette précaution est non moins indispensable avant d'entreprendre des expériences sur le pouvoir pathogène d'une souche. La grande majorité des résultats publiés jusqu'ici est sans valeur du fait des infections latentes, quelquefois très difficiles à déraciner.

L'examen microscopique ne renseigne en rien sur l'état de pureté d'une souche, seul le zymogramme, correctement établi et constant, permet ce contrôle.

Stemphylium polymorphum Bonorden 1851 (Hallier 1866), - II est à peine besoin d'insister sur cette dénomination qui, pour Candida albicans, n'a plus qu'un intérêt historique. Le genre Stemphylium Wallroth 1833 renferme des dématiées ou moisissures à thalle fuligineux au moins à la fin, à sporophore assez nettement distinct du mycelium, portant à son extrémité une seule spore très volumineuse, de couleur très foncée, cloisonnée en tous sens, du type spore murale. $S$. polymorphum est une espèce de Bonorden 1851 (p. 83, fig. 73). La confusion commise par Hallier vient très probablement de ses cultures très impures, dans lesquelles s'étaient développées des dématiées à spores murales (pl. IV, fig. 14-18), car il figure assez correctement d'autre part (pl. III, fig. 35-46) un champignon levuriforme qui peut être rapporté à $C$. albicans, à l'excep-

(1) Elle comprend plus de 100 dénominations pour une seule espèce ! Une seule étani valable, la centaine d'autres doit disparaitre dans le goufre synonymique. 
tion toutefois de la fig. 46 qui représente sans aucun doute un Cladosporium, autre dématiée trouvée aussi dans une culture. Les spores murales de dématiées sont extrèmement fréquentes dans les poussières, aussi est-ce une cause d'infections et d'erreurs qu'il importe de connaitre. C'est ainsi que Wilenczyk (1926-1929) (1) a déerit des spores de ce type comme des asques de Trichophyton e! d'Achorion.

Dematium albicans Laurent 1890 . - Le genre Dematium, auquel Laurent a rapporté le champignon du muguet, n'est certainement pas Dematium Persoon 1797 qui renferme des moisissures a thalle fuligineux, dont le conidiophore court porte de grosses chlamydospores arrondies, très foncées, naissant scuvent de protochlamydospores isolées ou en chaines. Il ne peut s'agir que du Dematium pullulans de Bary 1868, curieux champignon, pour lequel Mlle Berkhout a créé le genre Pullularia Berkhout 1923, p. 55. C'est encore une dématiée à thalle fuligineux, présentant une évolution très particulière, sur laquelle nous aurons l'occasion de revenir en faisant connaitre nos observations. Cette évolution, déjà étudiée par de Bary (1868), Laurent (1890), Planchon (1900), débute par une formation très active de blastospores (d'où le nom de pullulans). Mais il n'y a là qu'une analogie très superficielle, qui ne permet pas de maintenir ce rapprochement.

Mycotorula Will 1916. - La eritique de ce genre, on ne peut plus mal caractérisé, a été donnée par Langeron et Talice (1932, p. 43). Ces auteurs, dans leur étude morphologique des champignons levuriformes, n'avaient adopté celte dénomination que pour ne pas créer un terme générique nouveau. Actuellement, nous considérons que c'est un nomen nudum, ne correspondant à rien de précis.

Enantiothamnus Pinoy 1911. - La critique de ce genre a été donnée par Langeron et Talice (1932, p. 41-42). L'auteur en avait méconnu complètement la nature, puisqu'il en faisait un sporotriché ; pourtant les figures publiées montrent qu'il s'agit évidemment d'un champignon levuriforme filamenteux (mycotoruloỉdée). L. et T. l'avaient placé dans ce groupe et dans le genre Blastodendrion. Au cours du remaniement actuel, il a paru que l'hypothèse la plus vraisemblable était, malgré les lacunes de la description

(1) Ann. Inst. Pasteur, XLI, 1927, p. 1351-1356 (fig, 4 et 6). C.R. Soc. biol, XCVIII, 1928, p. 70 et fig-, 1049 ; CII, 1929, p. 113. 
originale, de rattacher Enantiothamnus braulti Pinoy 1911 au Candida krusei (voir plus haut, p. 41).

Trichosporum glycophile Du Bois 1910. - C'est de toute évidence un Candida albicans, comme le prouvent l'excellente description dont il a fait l'objet et les magnifiques planches en phototypie qui accompagnent le mémoire de Du Bois. Langeron et Talice (1931, p. 41) ont déjá établi cette identification et Langeron (Nouvelle Pratique dermatologique, t. II, 1936, p. 379-380) l'a confirmée en mettant en relief l'adaptation pilaire, si curieuse et inattendue, d'un champignon levuriforme.

Guilliermondella vuillemini (Lindau ?) C. W. Dodge 1935. Nous ne pouvons nous contenter de citer cette bizarre synonymie sans mentionner la série d'inexactitudes dont elle provient. L'espèce vuillemini n'est pas de Lindau (1), d'ailleurs Dodge fait prudemment suivre ce nom propre d'un point d'interrogation, mais il donne comme référence: Mikrokopische Pilze, 1912. Or si l'on consulte ce petit volume, édité par J. Springer à Berlin, on voit qu'à la page 66 , Lindau ne mentionne pas Endomyces vuillemini, mais seulement $E$. decipiens et $E$. magnusii. En réalité, l'auteur de cette espèce est bien Landrieu, comme Dodge l'a lu dans Castellani et Chalmers (1913). Le plus curieux est que Dodge cite précisément dans sa bibliographie (p. 399) le mémoire de Landrieu (Les mycoses oculaires, thèse Fac. Méd., Paris, 1912) sans le marquer de l'astérisque désignant les ouvrages non consultés: dans cette thèse, à la p. 106, Landrieu, d'accord avee Vuillemin, crée le nom d'E. vuillemini pour séparer la forme ascosporée du champignon du muguet de la forme anascosporée qui garde le nom de Monilia albicans.

Quant à l'attribution inattendue de cette espèce au genre Guilliermondella, nous sommes obligés de faire les plus expresses réserves. Ce genre a été créé en 1928 par Nadson et Krassilnikov pour des endomycétacées à mycélium bien développé, donnant de nombreuses conidies aériennes (2), pouvant à leur tour bourgeonner ou reproduire le mycélium. Il n'y a pas d'arthrospores. Les asques sont soit terminaux, soit intercalaires sur le mycélium ou même peuvent naître par transformation des éléments levuriformes. Les ascospores sont falciformes. C'est une levure azymatique, ne donnant, en moût de bière, ni voile, ni anneau.

(1) Lat mème confusion a été faite par Okabe $(1929, p, 186)$.

(2) Candida albicans ne possède pas d'organes aériens, comme Vuillemin l'a établi dés 1899 ; méme les chlamydospores sont immergées. 
Stelling Dekker (1931, p. 504-507) n'a pas accepté cé genre parce qu'il est insuflisamment caractérisé, la forme des spores permettant seule de séparer ce champignon des Endomycopsis. On sait en effet que, chez les levures ascosporées, la forme des ascospores est très variable : dans le mème genre on peut trouver les formes en anneau de Saturne, en chapeau melon ou en faucille, avec passages de l'une à l'autre. Quant au genre Endomycopsis, Stelling Dekker l'a créé pour séparer des Endomyces vrais ceux qui possèdent des conidies.

Voici quelle est, actueHement, à notre avis, la situation de l'Endomyces vuillemini vis-à-vis des genres Endomycopsis et Guilliermondella. En réalité, personne (1) n'a retrouvé les asques et les ascospores décrits par Vuillemin, sauf Okabe (1929, p. 184) qui n'a d'ailleurs pu les obtenir que sur gélose à l'extrait de koji et seulement au bout de 4-6 mois ; même dans ces conditions ils sont extrèmement rares et généralement ne renferment qu'une ascospore. Okabe dit néanmoins les avoir obtenus avec 45 souches sur 49. Il s'agissait bien de Candida albicans puisque les chlamydospores étaient toujours présentes, mais très lentes à apparaitre (plusieurs mois) et seulement sur des milieux spéciaux (lait de vache et gélatine au sirop de malt de millet). Les microphotographies publiées par Okabe sont absolument convaineantes pour les chlamydospores, mais bien moins pour les asques et ascospores qui ne présentent pas les particularités décrites par Vuillemin. Ce sont des arguments vraiment trop fragiles pour permettre de rattacher C. albicans à un genre de levures ascosporées. Nous pensons qu'il y a lieu de reprendre l'étude d'une collection de souches bien déterminées de $C$. albicans en les cultivant comme Vuillemin sur betterave et en suivant longtemps les colonies.

Vuillemin a étudié un véritable $C$. albicans : la figure qu'il donne d'un bouquet de chlamydospores en fait foi (Revue mycologique de Roumeguère, XXI, 1899, pl. CLXXXIX, fig. 6) ; cette figure est d'ailleurs reproduite dans tous les ouvrages classiques. Les asques sont représentés par les fig. $9,14 a$ et $b, 15,16 a$ et $b$ de la pl. CXC. Ils renferment tous quatre ascospores ovales ou réniformes, mais non falciformes, paraissant agglutinées (fig. $16 \mathrm{~b}$ ) par l'épiplasme. L'asque lui-mème parait enfermé dans une série d'enveloppes concentriques.

Stelling Dekker (1931, p. 228-230) a étudié une souche provenant de la collection Guilliermond et étiquetée Endomyces albicans,

(1) Shrewsbury (1934, p. 324) n'a pu les obtenir en suivant exaetement la technique de Vuillemin (1931). 
sans pouvoir arriver à reproduire les asques, mème sur milieux très favorables (moùt de bière liquide et gélosé ou gélatiné, blocs de plâtre, milieu de Gorodkowa, pomme de terre, carotte). Aussi ce champignon n'est-il placé parmi les Endomycopsis qu'en raison de la description de Vuillemin.

Actonia C. W. Dodge 1935. - Ce genre ne nous parait pas devoir être conservé. Il a trait à la levure décrite par Acton en 1918, d'après une souche provenant d'angines observées chez des soldats européens et hindous de l'armée anglaise de Mésopotamie. Si l'on se reporte, comme nous l'avons fait, au mémoire original d'Acton, on voit qu'il s'agit tout simplement de Candida albicans, parfaitement reconnaissable dans la pl. IV à ses chlamydospores. On ne peut sérieusement faire état des prétendus zoosporanges et zoospores: ce ne sont que des inclusions dans des chlamydospores. Quant aux asques, observés par Acton dans le liquide de Raulin, ce sont encore des chlamydospores méconnues, comme il ressort nettement de la description de la p. 596 du mémoire original. Tous ces artifices de préparation sont dus à une technique défectueuse : traitement du champignon par lalcool et la glyeèrine ou encore fixation par l'acide osmique [à 5 p. $100(1)$ ]. Un examen dans le Lugol double, ou plus simplement encore dans le liquide de culture; aurait évité toutes ces méprises, figurées d'une manière rudimentaire, ainsi que la création injustifiée d'un genre nouveau pour une espèce des plus banales. Actonia doit done disparaitre de la nomenclature mycologique et entrainer à sa suite des considérations théoriques qui ne reposent sur rien. Monilia actoni Vuillemin 1931 et Actonia tropicalis C. W. Dodge 1935 sont done synonymes de Candida albicans (Ch. Robin 1853).

\section{SOUCHES ÉTUdiÉEs}

\section{$1^{\circ}$ Souches nommées}

Mycotoruloides ovalis Langeron et Talice 1932. - Souche isolée, en novembre 1927, par le Médecin Principal Pichon, à l'Hòpital militaire de Coblentz, d'un cas de rhino-pharyngo-stomatite chez un soldat français de l'armée du Rhin. Souche $n^{\circ} 296 \mathrm{~A}$ (2).

Monilia psilosis Ashford 1917. - Deux souches originales d'Ashford, Porto Rico, sprue de l'adulte, $n^{\circ} 336 \mathrm{~A}$ et $340 \mathrm{~A}$.

(1) Cest bien cette concentration inusitće qui est donnée par Acton (1919, p. 594).

(2) Les numéros en italique zont ceux de la mycothèque de l'Institut de parasitologie de la Faculté de médecine de Paris (séries A et B). 
Monilia pinoyi Castellani 1910. - Cinq souches :

1. Souche originale de Castellani $1937, n^{*} 647 \mathrm{~B}$.

2. Souche provenant du Ross Institute de Londres, $n * 682 \mathrm{~A}$.

3. Souche communiquée par Ciferri et Redaelli, $n^{\circ} 581 \mathrm{~B}$.

4. Souche communiquée par Beintema (Groningue, Hollande), $n^{*} 625 \mathrm{~B}$.

Monilia pinoysimilis Castellani 1933. - Souche originale de Castellani, $n^{\circ} 509 \mathrm{~B}$.

Monilia inexorabilis Mazza et Palamedi 1931. - Souche $n^{*} 561 \mathrm{~B}$, souche Talice et Mackinnon $n^{\circ} 477$.

Monilia periunguealis Niño 1930 . - Souche $n^{\circ} 562 \mathrm{~B}$, souche Talice et Mackinnon $\mathrm{n}^{\circ} 468$.

Monilia alvarezsotoi Mazza, Niño, Quintana et Bernasconi 1931. Souche $n^{*} 563 \mathrm{~B}$, souche Talice et Mackinnon $n^{*} 471$.

Candida mycotoruloidea Redaelli et Ciferri 1935. - Souche $n^{\circ} 582 B$, souche originale de Redaelli $\mathrm{n}^{\circ} 12$.

Blastodendrion erectum Langeron et Talice 1932. - Souche $n^{\circ} 417$, provenant de la Collection R. Sabouraud à l'Hôpital St-Louis, sous le nom de muguet buccal à Endomyces albicans.

Blastodendrion oosporoides Zach 1933. - Souche $n^{\circ} 587$ B. Souche originale de Zach.

Monilia metalondinensis Castellani 1916. - Souche communiquée par le $\mathrm{D}^{r}$ Beintema de Groningue (Hollande), $n^{*} 628 \mathrm{~B}$.

\section{$2^{\circ}$ Souches non nommées}

\section{A. Levures da poumon}

Blastomcycosfs pulmonatres. - Souches Rivalier, Hôpital St-Louis, Paris, $193 \mathrm{~B}$; Guéniot, Maternitès, Paris, $516 \mathrm{~B}$ et $541 \mathrm{~B}$; de Brun du Bois Noir, Hôpital de Neuilly, cas Jolly $(779 \mathrm{~B})$.

Crachats. - Souches : Moraïtis, Alexandrie, 343 B; Panisset, Alfort, $374 \mathrm{~B}$; Maulel, Lorient, $553 \mathrm{~B}$.

Souches Aaser (Oslo, Norvège) (20 cas) (Aaser $n^{* *} 3 \alpha, 13,52,53,75,116$, $219 a, 223 a, 301,540,543,566,779 a, 4052,4087 a, 4189,4204 ; 4296 ; 5286 a$, 5396).

\section{B. Levures de la bouche}

Souches Guerra (Hôpital St-Louis, Paris).

Glossite médiane (9 cas), $436 \mathrm{~B}, 437 \mathrm{~B}, 439 \mathrm{~B}, 442 \mathrm{~B}, 451 \mathrm{~B}, 452 \mathrm{~B}$, $455 \mathrm{~B}, 457 \mathrm{~B}, 548 \mathrm{~B}$.

Leucoplasie buccale (1 cas), $441 B$.

Muguet de l'adulte (1 cas), $499 \mathrm{~B}$.

Abcès dentaires ( 2 cas), $4 \$ 4 \mathrm{~B}, 450 \mathrm{~B}$.

Souches Rouyer (Institut du radium, Paris), langue noire ( 2 cas), 4,2 bis $(807 \mathrm{~F}, \mathrm{~B}), 494$ bis $(807 \mathrm{G}, \mathrm{B})$.

Souches Catanei (Alger). 
Monilia du singe ( $43 \mathrm{~B}$ et $711 \mathrm{~A}$ ).

Souche Gaultier (Montréal, Canada).

Fistules de la bouche, du cou et des joues $(275 \mathrm{~B})$.

\section{Levures de I'intestin}

Souche Marchoux (Paris), Colite chronique (231 B).

\section{Levures de la peau}

Souche Ravaut (souche Cattiau) (160 B), Hôpital St-Louis.

Souches Guerra (Hòpital St-Louis).

Grands intertrigos avec levurides (8 cas), $438 \mathrm{~B}$, $443 \mathrm{~B}, 4.45 \mathrm{~B}$, $496 \mathrm{~B}, 447 \mathrm{~B}, 454 \mathrm{~B}, 476 \mathrm{~B}, 517 \mathrm{~B}$.

Intertrigo inguinal (1 cas), $453 \mathrm{~B}$.

Intertrigo anal (1 cas), $604 B$.

Psoriasis des plis (1 cas), $616 \mathrm{~B}$.

Balano-posthite (1 cas) (chez un diabétique), $492 \mathrm{~B}$.

Erosions interdigitales des mains (1 cas), $440 \mathrm{~B}$.

Erosions interdigitales des pieds (2 cas), $493 \mathrm{~B}, 518 \mathrm{~B}$.

Souche Dobkevitch (Hòpital St-Louis). Erosions interdigitales des pieds (1 cas) $(600 \mathrm{~B})$.

Souche Kara (Hópital St-Louis, service Milian). Epidermophytie du pied $(332 \mathrm{~B})$.

\section{E. Levures des ongles}

Sonche Reiss (Shanghaĩ) $(296 \mathrm{~B})$.

Souches Guerra (Hòpital St-Louis). Perionyxis de la main (6 cas), 448 B, $449 \mathrm{~B}, 456 \mathrm{~B}, 458 \mathrm{~B}, 474 \mathrm{~B}, 550 \mathrm{~B}$.

Souche Broughton Alcock (Londres). Perionyxis de la main (264 B).

Souche Sézari (Hòpital St-Louis). Onychomycose (335 A).

\section{F. Levure de I'all}

Souche Dobkeviteh. Conjonctivite d'un nourrisson (410 B).

a. Souches d'origine humaine, mais dont l'histoire n'est pas connue

1. Collection Sabouraud (Hòpital St-Louis).

636 A (Cryptococcus).

391 A (oïdiomycose, cas Lacloche).

403 A (oïdiomycose, cas Papadopoulos).

2. Souches Mazza (Buenos-Aires).

Monilia n" $22.744(143$ B).

Monilia $\mathrm{n}^{\circ} 23.306$ Mataco 61 (144 B).

3. Souches Ciarrochi (Rome, Scolastica Radice) (265 B et $266 \mathrm{~B}$ ).

4. Souches E. Sechi (Clinique dermatologique de Rome).

$322 B$, cas Profonder.

$323 \mathrm{~B}$, cas $\mathrm{Az}$. 
324 B, cas Caule.

$325 B$, cas Savi Stalia.

826 B, cas Pizzitutti.

5. Souches Horowitz (Paris) (4 souches, $\mathrm{n}^{* 3}$ 313-316 B).

6. Souches Milochevitch (Beograd, Yougoslavie).

$509(308 \mathrm{~B})$.

$488(309 \mathrm{~B})$, muguet.

$517(310 \mathrm{~B})$, muguet.

2369 (Institut d'hygiène) (617 et $660 \mathrm{~B})$.

2577 (Institut d'hygiène) $(661 \mathrm{~B})$.

2558 (Institut d'hygiène) $(659 \mathrm{~B})$.

7. Souche Beintema (Groningue, Hollande). Cas Lonof (629 B).

\section{H. Levures d'origine animale}

Souches communiquées par le Prof. Brumpl (Paris).

$147 \mathrm{~B}$, isolée de la patte d'un canard.

$189 \mathrm{~B}$, isolée de l'intestin d'un oiseau de Chine.

Historique. - Cette espèce est certainement la plus anciennement connue, ce qui est tout naturel, puisque c'est de beaucoup le champignon levuriforme le plus fréquent et le plus facile à observer chez l'homme. Il n'est donc pas surprenant que chaque fois que l'attention des observateurs s'est portée sur cette catégorie de parasites, on ait presqu'inévitablement rencontré cette espèce, C'est ce qui est arrivé pour Gruby (1842) et Robin (1853), parmi les précurseurs, et récemment pour Ravaut, dont la souche ayant servi à la préparation de sa levurine s'est trouvée être un Candida albicans (souche Cattiau $160 \mathrm{~B}$ ).

C'est donc à ce champignon qu'il faut toujours penser, surtout dans les pays tempérés, lorsqu'on isole une levure de la bouche, de l'arrière-bouche, des crachats ou de la peau. L'apparition des chlamydospores, soit dans l'épaisseur de la gélose autour des colonies géantes en tubes, soit dans les colonies sur lames, ou encore en cellule en milieu liquide (milieu P. C. liquide, non gélosé, voir p. 68) permet d'en faire la détermination immédiate. II est donc très facile à reconnaitre, presque sans manipulations ; les autres procédés d'étude pourront servir à la confirmation du diagnostic basé sur la présence des chlamydospores.

Il est inutile de nous étendre sur l'historique de cette espèce qui ressort de la synonymie établie plus haut. Cette longue liste de dénominations génériques et spécifiques suffit à montrer les vieissitudes par lesquelles a passé cette levure pourtant si facile à reconnaître. 


\section{Caractères macroscopiques des cultures}

1. Gélose glycosée à 2 p. 100. - Colonies blanches, crémeuses, humides, lisses, assez convexes, à bords lisses.

Filamentisation. - L'apparition de filaments autour des colonies est assez variable: quelques souches donnent une filamentisation précoce et très abondante; d'autres peuvent rester des mois sans produire de filaments. En règle générale, on peut dire que les vieilles souches conservées depuis longtemps au laboratoire filamentent plus facilement que les souches récemment isolées.

La filamentisation de $C$. albicans présente certains caractères utiles à connaître :

1. Elle est irrégulière et ne forme jamais une couronne de rayons équidistants. Quelques filaments s'éloignent très loin du centre de la colonie, d'autres sont courts et touffus.

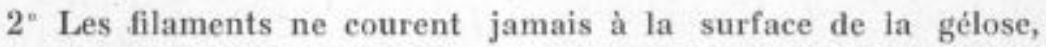
mais ont une tendance marquée à pénétrer très loin en profondeur. Ce phénomène n'est évidemment visible que dans les $2^{*}$ et $3^{*}$ colonies telles qu'on les obtient en suivant notre méthode d'ensemencement en tube (voir plus haut, p. 56 et 57).

Nous avons dit que la surface des colonies est lisse, mais, dans les vieilles cultures, elle peut présenter des irrégularités, papules, enfoncements, etc., qui n'ont aucune importance systématique.

Cette surface peut encore être modifiée par des variantes membraneuses ou à secteurs sombres. Ces variantes, qui feront l'objet d'une étude particulière, sont plus ou moins facilement réversibles au type normal, décrit ci-dessus.

2. Milieu liquide glycosé à 2 p. 100. - Dans ce milieu, C. albicans donne très rapidement un anneau régulier et un dépót abondant, mais jamais de voile. II faut cependant faire une exception pour les souches très membraneuses ou devenues telles, qui peuvent donner des voiles membraneux tombant facilement au fond par agitation du tube.

Ces voiles membraneux s'observent surtout dans les tubes qui ont servi aux épreuves de fermentation. Une fois le bouchon de paraffine chassé en haut par la pression du gaz, la surface libre du liquide se couvre d'un voile membraneux assez épais et solidement tissé. Il importe de noter que ce voile se forme en atmosphère carbonique; il est done tout à fait indépendant de l'action stimulante de l'oxygène.

Mais, dans les cultures normales à l'air libre, le voile membra- 
neux n'est produit, chez $C$. albicans, que par les variantes membraneuses. Il apparait toujours tardivement, au bout de 10 à 15 jours.

Les variantes à secteurs sombres peuvent donner, exceptionnellement, une fugace pellicule muqueuse.

3. Liquide de Raulin. - Ni voile, ni anneau. Les souches très membraneuses donnent de petites colonies blanches, bien individualisées, qui ne troublent pas le liquide par agitation.

\section{Alcool à 3 p. 100. - Développement moyen sous forme de dépôt.}

5. Lait. - N'est pas modifié dans les délais normaux, lorsque les souches sont pures.

\section{Morphologie microscopique.}

Lorsque C. albicans vient d'ètre isolé, il peut ne donner, pendant un certain temps, sur gélose glycosée, que des blastospores.

La filamentisation est facile et constante en eau de pommes de terre (Talice 1930 ; Langeron et Talice 1932 ) ; $C$. albicans s'y développe, si l'ensemencement est pauvre, sous forme de colonies filamenteuses qui, par agitation du tube, simulent un nuage.

Nous avons expliqué que l'étude de ces colonies, développées en milieu liquide, est très difficile, car leur prélèvement détruit plus ou moins totalement l'appareil sporifère qui est d'une excessive fragilité.

C'est pourquoi nous nous sommes efforcés d'adapter à l'étude des champignons levuriformes la méthode de culture sur lames gélosées de Rivalier et Seydel et de réaliser sur ces lames des conditions identiques à celles que le champignon trouve dans l'eau de pommes de terre.

Nous avons ajouté de l'eau de carottes, pour favoriser éventuellement la production des asques. Pour réaliser les conditions d'anaérobiose relative qui règnent au fond d'un tube garni de liquide, nous avons placé nos lames en atmosphère carbonique, suivant la méthode de Magnusson. Dans ces conditions, la filamentisation se produit à coup sùr et très rapidement.

Molliard (1935) a signalé l'action de l'anhydride carbonique sur l'élongation des cellules. Nous avons, de notre còté, constaté que c'est bien $\mathrm{CO}^{2}$, et non le manque d'oxygène, qui provoque cette filamentisation rapide (voir plus haut, p. 68). 
Chlamydospores. - L'examen et la lecture de notre illustration montreront combien la morphologie microscopique de $C$. albicans peut être variable. Elle présente pourtant un élément très caractéristique qui lui est propre: les chlamydospores. Ce sont de grosses cellules sphériques, réfringentes, à double contour, tonjours terminales; elles sont acidophiles et acido-résistantes par la méthode de Kufferath; elle ne bourgeonnent ni ne germent jamais sur place comme l'indique déjà Vuillemin (1899). Leur évolution n'a lieu que si on les change de milieu, phénomène déjă constaté par Ostrowsky (1896).

Ces chlamydospores ont été vues et figurées par beaucoup d'observateurs, mais on les a toujours considérées comme un élément banal et fortuit. On ne les a jamais rattachées à une entité spéeifique déterminée.

Or pour nous elles sont un élément essentiel de la morphologie du groupe albicans. Nous ne les avons jamais rencontrées chez d'autres espèces. Tous les champignons levuriformes présentant des chlamydospores ainsi définies possèdent exactement les mêmes propriétés biologiques et une morphologie analogue. Inversement, tous les champignons levuriformes qui présentent les mêmes caractères biologiques et morphologiques que C. albicans donnent ces chlamydospores. Elles sont donc une des meilleures caractéristiques morphologiques de cette espèce, qu'elles permettent de reconnaitre immédiatement.

Ces éléments, parfaitement décrits par Vuillemin (1899) qui les nomme chronispores, ont été découverts par Grawitz en 1877, dans de vieilles cultures épuisées : Kehrer les obtient en 1883 sur du sable humide ; Plaut (1887) les trouve constamment dans les cultures àgées et même quelquefois dans le muguet des animaux épuisés : Roux et Linossier (1890) les voient dans le liquide de Naggeli saccharosê, Grasset (1893) dans des cultures anciennes en bouillon, Radais (1896) sur blocs de plàtre. Vuillemin a bien insisté sur le fait que ces organes ne sont jamais aériens, même Jorsqu'ils terminent une série de rameaux disposés en bouquet ou corymbe : ces appareils prennent toujours naissance dans la profondeur du milieu liquide ou de la gélose : ce dernier cas est facile à constater au microscope en examinant par transparence les tubes dans lesquels se développent les colonies géantes. Les chlamydospores n'ont done rien de commun avec les conidies; elles font partie de ce que Vuillemin a nommé \& formes de concentration 3. Ce sont des organes de conservation, bourrés de matériaux de réserve, sous forme de grosses granulations qui ont été prises quelquefois pour des ascospores (Acton 1918). 
II y a des souches qui donnent difficilement ou seulement très tardivement des chlamydospores, leur absence n'est donc pas éliminatoire pour albicans si les autres caractères concordent. Nous verrons plus loin que des souches présentant les caractères de C. triadis peuvent ainsi donner des chlamydospores. En somme, cet organe caractérise le groupe albicans.

Protochlamydospores. - Dans la plupart des cas, les chlamydospores naissent sur un article renflé, qui est le siège d'une forte condensation protoplasmique et qui, par conséquent, fixe intensément les colcrants. Cet article déjà vu par Plaut (1887) a été figuré plus ou moins nettement par divers auteurs (Vuillemin, 1899, Langeron et Talice, 1932, etc.), mais Roux et Linossier (1890, p. 22-23) paraissent être à la fois les premiers et les seuls à avoir compris sa véritable valeur. Leur description et les figures qui l'accompagnent sont tout à fait significatives.

Nous donnons à cet article le nom de protochlamydospore et nous le considérons comme homologue de la phialide. Tous deux condensent énergiquement le cytoplasme des articles du filament qui leur donne naissance et emploient ces réserves à la formation de chlamydospores ou kystes de conservation pour l'un et de conidies ou spores de dissémination pour l'autre. La protochlamydospore une fois son ròle accompli s'allonge et se vide au profit de la chlamydospore.

Les chlamydospores ne sont pas toujours strictement terminales : elles peuvent naitre latéralement. Le plus souvent elles sont isolées, mais la protcchlamydospore peut aussi les produire par bouquets de deux ou trois ou mème par chaînettes de deux éléments.

La protochlamydospore peut quelquefois se transformer ellemème en chlamydospore allongée, en s'entourant d'une membrane à double contour : ce phénomène est extrẻmement fréquent dans certaines lames. Ce qui montre que ce sont bien de véritables chlamydospores e'est qu'elles deviennent acido-résistantes.

Enfin la protochlamydospore peut être absente et alors les chlamydospores sont sessiles, ce qui est aussi assez fréquent.

Dans un mémoire sur le genre Monilia, paru en 1934, Shrewsbury (J. F. D.) a longuement étudié les champignons levuriformes.

La morphologie microscopique décrite par cet auteur nous a paru singulièrement compliquée. S'il avait eu connaissance du travail de Langeron et Talice (1932), sa tâche aurait peut-être été simplifiée. Ces auteurs avaient très nettement décrit le pseudomycelium des Candida, 
fort mal défini par Shrewsbury. Pour nous, ses « adolescent cells, adult cells, ring cells, balloon cells, fat cells, shadow cells s sont des blastospores à différents àges, les premières en pleine activité de bourgeonnement, les dernières des éléments âgés ou mème morts et vacuolisés.

Les \& sprout cells ? sont nos pseudo-conidies que cet auteur n'a pas distinguées des blastospores. Pourtant, dans sa fig. 7, qui est bien démonstrative, on voit nettement ces éléments naissant latéralement (pleurogènes) sur un article du pseudomycelium, insérés sur un denticule et . par un processus entièrement différent du bourgeonnement.

Quant aux chlamydospores, dont l'acido-résistance est pourtant notée, elles sont confondues avec ce que Shrewsbury nomme \& gemmae \$. Ainsi, dans sa fig. 8, les chlamydospores et leurs protochlamydospores sont parfaitement figurées sous le nom de gemmae; dans la fig. 9 , on voit, sous le mème nom, un autre bouquet de chlamydospores et les \& few bizarre fllaments * sont des protochlamydospores très reconnaissables. A la p. 322, les protochlamydospores sont mentionnées sous le nom de * collecting cells * de Vuillemin, et l'auteur dit les avoir toujours vues en rapport avec les gemmae. En somme, Shrewsbury nomme gemmae nos chlamydospores. Cette distinction ne nous parait pas utile, les chlamydospores se formant toujours, dans tous les groupes de champignons, par un phénomẻne de condensation protoplasmique. Celles des Candida sont exactement conformes à cette règle. Enfin, il n'est pas tout à fait exact de dire qu'elles ne forment jamais de chainettes: ces chainettes sont rares, mais elles peuvent exister, elles sont très courtes et formées de deux ou trois éléments. Il est aussi inexact de dire que les chlamydospores des Candida sont toujours isolées que de considérer les conidies des Scopulariopsis comme formant toujours des chainettes : elles peuvent au contraire ètre très volumineuses et isolées, ce qui a donné lieu à de bien singulières méprises dont nous parlerons ailleurs.

Shrewsbury insiste longuement sur les différences qu'il constate entre les conidies des Monilia vrais et les chlamydospores des Candida. Cette distinction est évidente et saute aux yeux : elle est encore accentuée par la présence, dans les conidies des Monilia, de disjonctenrs, organes que l'auteur figure (fig. $10, \mathrm{pl}$. XLV) mais dont il ne parle pas. Notons à ce propos que la différence entre les Monilia vrais et les Candida, déjà indiquée par Vuillemin (1911), a été très précisément établie par Langeron et Talice dès 1932 (p. 34-37, fig. 13-14).

Globules internes de Vuillemin. - Tous les traités classiques reproduisent la figure 11 de la pl. CXC du mémoire de Vuillemin (1899). Cette figure, examinée à la lumière des connaissances récemment acquises, représente deux articles d'un pseudo-mycélium de Candida. L'article inférieur porte eing spores que nous interprétons comme des pseudo-conidies, toutes insérées sur un denticule et faisant partie d'un manchon dont les denticules sub- 
sistent seuls pour quatre ou cinq autres spores. L'article supérieur est plus difficile à interpréter. Il renferme une file de sept éléments ovalaires, dont l'inférieur est plus allongé : Vuillemin, très affirmatif, considère ces éléments comme des endospores. Dès 1853, Ch. Robin a vu et figuré des formations analogues, Quinquaud, Plaut paraissent les avoir décrits plus ou moins confusément. Roux et Linossier, puis Noisette, en nient formellement l'existence. Ajoutons que personne, à notre connaissance, ne les a revus depuis Vuillemin. Au cours de plus de huit années de recherches, nous ne les avons jamais aperçus (Langeron et Talice, 1928-1931, Langeron et Guerra 1932-1937). Notons aussi que les endospores véritables sont très rares chez les champignons. Il est done à eraindre que ce Maître éminent ait été victime d'une illusion d'optique due à une technique imparfaite; il reconnait d'ailleurs lui-même que ces éléments * ne présentent pas la constitution morphologique des spores 3. La question reste done ouverte, comme pour les asques, et sera peut-être résolue le jour où quelqu'un observera de nouveau des formations analogues.

\section{Caractères biologiques}

Zymogramme. - Positif pour : glycose, lévulose, maltose, galactose (faible); négatif pour: saccharose, lactose, raffinose.

Il peut arriver qu'on constate avec le saccharose l'apparition d'une bulle de gaz, mais il n'y a jamais séparation nette du bouchon de parafline.

Auxanogramme des sucres. - Positif pour : glycose, maltose, galactose, saccharose; négatif pour : lactose et raflinose.

Auxanogramme de i'azote. - Positif pour : peptone, asparagine, glyleocolle, histidine, tryptophane, sulfate dammonium; positif et tardif pour l'urée et sous la forme d'une zone très étendue et très peu opaque; négatif pour nitrate de potassium.

\section{LECTURE DES PLANChES XII-XVI}

A) Types de filamentisation. - 1. Type Mycotorula. - Ce type est représenté par les fig. 3 , pl. XIII, 1 et 2 , pl. XII, qui en montrent le cycle de développement. Ces aspects sont fournis par la souche Borokevitch, n* 448 B, cultivée sur lames gélosées, couvertes de milieu $\mathrm{PC}$ et en atmosphère carbonique.

La fig. 3, pl. XIII montre des rameaux issus de filaments plus profonds; ces rameaux portent de petits vertieilles simples et sont géní- 
ralement terminés par un bouquet de 2-3 blastospores. C'est cet aspect, observé par Langeron et Talice en eau de pommes de terre a $37^{\circ}$, qui avait servi de type pour leur genre Mycotorula. Ici ces courts rameaux ont pris naissance sur une lame assez sèche, en culture depuis quelque temps et en atmosphère carbonique pauvre.

Les fig. 1 et 2, pl. XII montrent l'aspect typique Mycotorula avec verticilles réguliers en forme de glomérules arrondis.

II est curieux de constater que cet aspect est un des plus difficile à obtenir et des plus rarement constatés dans les cultures sur lames. Il faut que celles-ci soient suflisamment épaisses et humides, autrement les verticilles s'étalent et s'aplatissent.

Cet aspect n'est en rien caractéristique du C. albicans, chez lequel il se rencontre rarement dans les conditions ordinaires de nos cultures sur lames. On le trouve aussi chez beaucoup d'autres Candida et mème chez des champignons très éloignés de ce groupe, comme les Torula.

Un aspect très voisin est présenté par la souche qui nous a été obligeamment envoyée par le Prof. Castellani, comme étant le Monilia pinoyi type (fig. 1, pl. XIII, culture de 6 jours sur milieu P.C.). Du filament axial se détachent des rameaux à verticilles simples ; ces rameaux se terminent par un bouquet de blastospores.

2. Type Mycotoruloides. - Ce type, à verticilles composés, étalés, non globuleux, est bien représenté par la souche $160 \mathrm{~B}$ (Cattiau) (1). Cet aspect est très fréquent sur gélose glyeosée à 2 p. 100. Les filaments se terminent tantòt par un long fouet, formé de longues blastospores baculiformes, tantòt par un bouquet de blastospores comme dans le type Mycotorula (fig. 3, pl. XII).

Le Candida pinoyi peut prendre aussi l'aspect Mycotoruloides comme le montre la fig. 3, pl. XIV (souche 682 de la Mycothèque de I'Institut de parasitologie, provenant du Ross Institute de Londres, communiquée par le Prof. Castellani avec la détermination de Monilia pinoyi, nommée Blastodendrion pinoyi, par Langeron et Talice 1932). Remarquer, dans cette figure, les verticilles du type mycotoruloides, la présence de quelques pseudo-conidies et la grande dimension des blastospores. Ce qui montre bien qu'il s'agit de $C$. albicans, c'est la présence, en d'autres points de la préparation, de longs filaments portant des chlamydospores typiques.

B) Chlamydospores. - La fig. 4, pl. XIV représente des filaments de $C$. albicans chargés de chlamydospores typiques. Ces éléments

(1) Cette souche était conservée au Laboratoire depuis plus de einq ans lorsque la culture sur lame a été faite.

ANmales ne Panasitologie, 7. XVI, $x^{\circ} 5 .-1$ - 5 septembre 1938. 
apparaissent en général soit à la base des filaments, presque sur la strie d'ensemencement, soit au contraire tout à fnit à l'extrémité distale des filaments, quelquefois très loin (3 mm. et plus) de la strie d'ensemencement.

La fig. 4, pl. XIII (souche Govain 517 B, milieu P.C. en atmosphère earbonique) montre de jeunes chlamydospores en voie de formation : la membrane à double contour et l'acido-résistance n'ont pas encore apparu. Entre les longs filaments porteurs de chlamydospores, on voit d'autres filaments chargés de verlicilles de blastospores, composés et étalés, du type Mycotoruloides.

La fig. 2, pl. XIII (souche 403 A, lame de 12 jours, milieu P.C.) (1) représente la filamentisation lusuriante el rapide d'une souche membraneuse de $C$. albicans. A l'extremité de longs filaments, on voit des chainettes de gros eicirents qui s'allongent et prennent un aspect monilifforme. Ces éléments sont des protochlamydospores. Ils peuvent donner naissance non stufement à des chlamydospores, mais aussi à des bourgeons latéraux et subterminaux. Lorsque la protochlamydospore s'allonge, ces bourgeons peuvent simuler des ramifications latérales d'un filonient vrai. Cet aspect se retrouve chez le Candida mycotoruloidea de Redaelli et Ciferri (1935), chez le Mycotoruloides ovalis de Langeron et Talice (1932), ainsi que dans beaucoup d'autres souches.

C) Pseudoconidies. - La souche $403 \mathrm{~A}$ (fig. 1, pl. XIV) nous fournit encore un exemple intéressant de la formation des pseudo-conidies et des chainettes moniliformes, composées d'articles à base renflée. Lorsque ces chainettes se détachent, elles peuvent simuler un pseudo-mycelium à articles stalagmoïdes (forme Blastodendrion, de Langeron et Talice). Remarquer sur cette figure les manchons de pseudo-conidies.

D) Variations diverses de la morphologie de c. albicans, a) Action de $\mathrm{CO}^{2}$, - La fig. 2, pl. XIV montre bien l'exagération de la filamentisation produite par une atmosphère très riche en $\mathrm{CO}^{2}$ (souche 160 B Cattiau, milieu P.C.). Pour que l'effet se produise pleinement, il faut que le milieu soit très humide, pour ainsi dire semi-fluide, de manière à provoquer l'enroulement désordonné du pseudo-mycelium. Remarquer en mème temps l'absence totale de

(1) Cette souche est conservée depuis 1930 dans la Mycothèque de I'Institut de parasitologie. Elle provient de la collection Sabouraud, oú elle figurait sous le nom d'oldiomycose, cas Papadopoulos, sans autre indication. Langeron et Talice (1932) l'ont rangée dans leur genre Mgeotorula, sans détermination spéeiflque. Clest un Candida albicans. Cette souche, actuellement trés membraneuse, étaît crémeuse au moment oủ elle a été étudiée par Langeron et Taliee. 
blastospores (dans la zone photographiée, car il y en avait en d'autres points de la lame). Pourtant cette souche avait été prise pour un Cryptococcus par les auteurs qui l'ont étudiée les premiers, à cause de labsence de filaments.

b) Action des modifications apportées au milieu pendant la culture. - La fig. 1, pl. XV (souche $561 \mathrm{~B}=477$ Mackinnon $=$ Monilia inexorabilis Mazza et Palamedi 1931; culture de 15 jours sur milieu P.C.) est extraite d'une lame arrêtée dans son développement et à laquelle on a ajouté un peu de glycose. Il en est résulté, d'une part l'apparition de chainettes latérales formées de blastospores allongées (aspect Candida de Langeron et Talice), d'autre part le bourgeonnement de chlamydospores mùres et acido-résistantes (fortement colorées en rouge sur la préparation) avec formation de chainettes de blastospores (fig. $4, \mathrm{pl}, \mathrm{XVI}$ ).

La fig. 3, pl. XVI (souche $563 \mathrm{~B}=471$ Mackinnon = Monilia alvarezsotoi Mazza, Nin̄o, Quintana et Bernasconi 1931) provient d'une lame de 15 jours sur milieu P.C. Après dessiccation, cette lame a séjourné à l'étuve à $37^{\circ}$ pendant 24 heures et enfin a été retrempée dans de l'eau peptonée, glycosée à 4 p. 100 , pendant 30 secondes. Elle a ensuite été placée de nouveau dans un tube Borrel en chambre humide, en étuve à $25^{*}$ pendant 24 heures. On voit de grosses pseudo-conidies s'étirer et bourgeonner, pour donner finalement un aspect tout à fait semblable à celui que Ciferri et Redaelli ont figuré (1935, p. 38, fig. 23) sous le nom de Mycotorula verticillata.

Le même aspect a été réalisé fortuitement (fig. 3 , pl. XV) dans une lame de la souche $682 \mathrm{~A}$, communiquée par le Prof. Castellani sous le nom de Monilia pinoyi et provenant des collections du Ross Institute de Londres. Cette figure montre un vieux filament qui, probablement à la suite d'un choc, a été mouillé par le liquide se trouvant au fond du tube Borrel et dont les pseudo-conidies se sont mises à bourgeonner. Un autre fllament (pl. XVI, fig. 5) porte des protochlamydospores et des chlamydospores.

Des accidents de ce genre expliquent beaucoup d'aspects qui pourraient être pris pour des caractéristiques morphologiques et inciter à créer de nouvelles espèces, basées seulement sur ces formes accidentelles.

La souche 563 B, dans une lame de 25 jours sur milieu P.C., montre (fig. 1, pl. XVI) la germination sur place des blastospores d'une colonie membraneuse et des manchons plus ou moins allongés de pseudo-conidies.

c) Variations spontanées. - Nous prendrons comme exemple 
notre souche $417 \mathrm{~A}$, provenant de la collection Sabouraud, sous le nom d'Endomyces albicans, muguet buccal, conservée depuis 1930 dans la Mycothèque de l'Institut de parasitologie, étudiée par Langeron et Talice (1932), et nommée par eux Blastodendrion erectum.

La fig. 5, pl. XV montre la forme Mycotorula typique, avec verticilles réguliers et globuleux (culture de 8 jours sur gélose glycosée à 2 p. 100) ; la fig. 2 , pl. XV (culture de 3 jours, sur milieu P.C.) représente un rameau portant des verticilles à chainettes latérales (du type Candida de Langeron et Talice) ; la fig. 4, pl. XV (culture de 6 jours sur milieu P.C., à $37^{\circ}$ ) donne l'aspect Blastodendrion à verticilles dressés, appliqués sur l'axe, tel que l'ont défini Langeron et Talice (1932). Cette figure présente encore un autre détail très intéressant : ce sont des renflements du filament axial, qui sont le siège d'un bourgeonnement simple ou double.

Dans la fig. 2, pl. XVI (culture de 8 jours à $25^{\circ}$ sur gélose glycosće a 2 p. 100, en atmosphère de $\mathrm{CO}^{2}$ ), on voit des chlamydospores sessiles immatures (qui ont peut-être donné en germant un aspect analogue à celui de la fig. $4, \mathrm{pl}$. XVI). Remarquer que les blastospores au lieu d'être stalagmoïdes, comme il se devrait chez un Blastodendrion, sont parfaitement sphériques.

Ces quatre exemples de variations d'une mème souche montrent l'étonnante plasticité des champignons levuriformes et le peu de confiance que l'on doit accorder à la morphologie pour la systématique de ce groupe. Seule la méthode des cultures sur lames, en permettant de suivre longuement l'évolution des colonies et en fournissant des préparations durables montées au baume, a pu résoudre ce problème et prouver que le critère morphologique ne peut suffire pour la delimitation des espéces de ce groupe. On peut dire maintenant que les espèces de levures basées uniquement sur la morphologie sont vouées à tomber tôt ou tard en synonymie.

\section{CANDIDA TRIADIS (Langeron et Talice 1932)}

L'historique de cette espèce a été donné dans le mémoire de Langeron et Talice (1932, p. 48). La souche, conservée dans la Mycothèque de l'Institut de parasitologie sous le n" $587 \mathrm{~A}$, provient de la collection du Prof. Guilliermond. Eile a été isolće, en mars 1925, à l'Hôpital mixte de Saumur, des crachats d'un spahi algérien hospitalisé pour accidents pleuro-pulmonaires. Elle a fait l'objet d'une première étude, en 1927, par Brocq-Rousseu, Guilliermond et des Cilfeuls et a été décrite par ces trois auteurs sous 
le nom de Monilia sp., sans qu'il lui ait été attribué de nom spécifique. Langeron et Talice (1932) en ont fait le type de leur genre Mycotoruloides et lui ont donné le nom de $M$. triadis, pour rappeler les recherches des trois auteurs qui s'en sont occupés les premiers. Une nouvelle étude de cette souche, nous a montré que, par ses caractères biologiques, elle est très voisine de $C$, albicans.

\section{SOvches ÉTUdTÉs}

La souche $587 \mathrm{~A}$ a èté longtemps le type unique de cette espèce. Dans la collection de levures envoyée d'Oslo à l'un de nous par le $\mathrm{D}^{x}$ Aaser, C. triadis s'est trouvé richement représenté par une série de 53 souches sur 85 , donnant des colonies gèantes de teinte ivoire, non membraneuses, à filamentisation très irrégulière, formant constamment un voile sur eau glycosée peptonée et souvent aussi en alcool : $\mathrm{n}^{\circ *} 24,30 a, 33,49,58,59 b$, $66 b, 68,82,84,130,131,133,135,168,196,200 c ; 223 b ; 242 ; 247 ; 249 b$, $253,268 b, 270 a, 272 a, 280 b, 287 a, 287 b, 292 a, 293 b, 295,302 ; 328 ; 341 a$, $341 b, 355 b, 409,424,457 b, 518 b, 524 b, 544 a, 580,590 b, 591 ; 715,851 b$; $863 b, 4125,5065,5252,5283,5354$.

Souche Douvier (Grenoble), crachats $(663 \mathrm{~B})$.

Souche Peyre (Paris), cas Brégier, crachats $(795 \mathrm{~B})$.

Souche Lemierre (Hôpital Claude Bernard), levure de la langue $(799 \mathrm{~B})$.

Souches Rouyer (Institut du radium), langue noire, 160 bis $(807 \mathrm{E}, \mathrm{B})$, 440 bis $(807 \mathrm{D}, \mathrm{B}), 517$ bis $(807 \mathrm{G}, \mathrm{B})$.

\section{Caractères macroscopiques des cultures}

1. Gélose glycosée à 2 p. 100, - Colonies semblables à celles de $C$. albicans; elles ne s'en distinguent que par leur teinte un peu plus jaunâtre. Nous n'avons jamais observé pour cette souche ni variante membraneuse, ni apparition de secteurs sombres.

Filamentisation. - Irrégulière et n'apparaissant pas toujours.

2. Milieu liquide glycosé à 2 p. 100. - Pendant les premiers jours, végétation sous forme de dépôt, puis, assez brusquement, vers le $13^{*}$ jour, apparition d'un voile muqueux, très net, qui peut se plisser, et d'un anneau de $2-4 \mathrm{~mm}$. de hauteur.

Ce caractère du voile et de l'anneau est très important, car il sépare cette espèce du $C$. albicans.

3. Liquide de Raulin. - Ni voile, ni anneau.

4. Alcool à 3 p. 100. - Voile et anneau légers et inconstants; le voile est quelquefois remplacé par des ilots. Développement généralement abondant.

5. Lait tournesolé, - Peu modifié, léger virage au bleu. 


\section{Morphologie microscopique}

La filamentisation sur lame est assez difficile à obtenir. Les milieux qui nous ont paru les plus favorables sont le milieu P.C et surtout le milieu de Gorodkova. L'aspect général est celui du type mycotoruloides de Langeron et Talice.

La souche $587 \mathrm{~A}$ n'a jamais donné de chlamydospores mais, parmi les 53 souches de la collection Aaser que nous rapportons a C. triadis, 33 ont donné des chlamydospores, tandis que sur les 32 souches que nous considérons comme albicans, 19 ont donné des chlamydospores.

Albicans et triadis sont done deux espèces extrêmement voisines, qu'il y aura peut-être lieu de réunir en une seule, car leurs propriétés biologiques sont à peu près identiques et toutes deux peuvent donner des chlamydospores.

\section{Caractères biologiques}

Zymogramme. - Positif pour : glycose, maltose, en général (forte fermentation), galactose (très faiblement); négatif pour : saccharose, lactose, raffinose. Ces réactions sont celles que donne C. triadis en eau peptonée. Mais si les fermentations sont faites dans l'eau de levure, cette souche fait fermenter fortement le galactose et assez fortement le saccharose.

Auxanogramme des sucres, - Positif pour: glycose, maltose, galactose ; négatif pour : lactose, rafifinose.

Auxanogramme de l'azote. - Posilif pour: peptone, asparagine, histidine, glycocolle et sulfate d'ammonium ; faible, tardif et pen net pour : urée ; négatif pour : nitrate de potassium.

\section{LECTURE des PLANCHES}

1. Aspect Mycotoruloides. - Bien représenté par la fig. 2, pl. XXI: on voit partir du filament axial des verticilles composés, irréguliers et étalés.

Une culture de 5 jours à $25^{\circ}$ sur milieu de Gorodkova, en atmosphère carbonique, montre à un plus fort grossissement (fig. 1 pl. XXII), la structure des verticilles. Remarquer :

1. Le volume et la netteté du filament axial qui semble être un filament de mycelium vrai, cloisonné.

2. La naissance subapicale des verticilles. Dans le $1^{\text {er }}$ verticille 
à partir du bas et à gauche, on verra la naissance d'un filament secondaire.

3. La forme et le volume des blastospores, grandes, allongées, monomorphes, avec tendance à former des chainettes.

2. Polymorphisme des blastospores, - La fig. 1, pl. XXI (culture de 5 jours a $25^{\circ}$ sur milieu de Gorodkova), montre la coexistence. sur le même rameau, de blastospores du type normal et de blastospores baculiformes. Comme nous avons observê le même phéno mène chez certaines souches de $C$. albicans (souche $296 \mathrm{~A}$, ovalis à secteurs sombres), nous nous sommes demandé si $C$. triadis ne serait pas une variante sombre stabilisée de $C$. albicans.

\section{II. - GROUPE TROPICALIS}

Ce groupe diffère du groupe albicans parce qu'il fait fermenter le saccharose (en plus du glycose et du maltose).

\section{Eléments morphologiques :}

a) Filamentisation très variable suivant les espèces, toujours bien moins régulière que dans le groupe albicans : aspect Mycotoruloides, avec verticilles, aspect Candida avec longues chainettes, aspect Mycocandida avèc longs filaments et verticilles très réduits (rameau de sapin).

b) Blastospores arrondies ou ovalaires, généralement monomorphes, moins nombreuses que dans le groupe albicans,

c) Chlamydospores absentes.

d) Pseudoconidies remarquablement développées chez $C$. tropicalis, dont elles sont un des meilleurs caractères morphologiques et chez lequel elles forment des chainettes simples ou plus ou moins ramifiées (type Candida de Langeron et Talice).

2. Zymogramme de levures zymato-osidasiques, malto-saccharasiques, positif pour glycose, maltose, saccharose.

3. Auxanogramme des sucres négatif pour lactose et raffinose.

4. Auxanogramme de l'azote négatif pour l'urée.

5. Eléments systématiques. - Trois espèces :

C. tropicalis (Castellani, 1910).

C. intermedia (Ciferri et Ashford, 1929).

C. pelliculosa Redaelli, 1925. 
CANDIDA TROPICALIS (Castellani 1910) Berkhout 1923, p. 43

1901 ? Saccharomyces lingure-pilose Lucet 1901, p. 262.

1910 Oidium tropicale Castellani 1910 , p. 197.

1911 Endomyces paratropicalis Castellani 1911, p. 236.

\& Monilia bonordeni Vuillemin 1911, p. $140 \rightarrow$ (C. W. Dodge 1935, p. 270).

1912 Endomyces bronchialis Castellani 1912, p. 1208.

E. entericus Castellani 1912, p. 1208.

E. insolitus Castellani 1912, p. 1208.

1913 Endomyces pulmonalis Castellani 1913, p. 184.

E. burgessi Castellani 1913, p. 184.

E. perryi Castellani 1913, p. 184.

Monilia tropicalis Castellani et Chalmers 1913, p. 824.

1918 Endomyces cruzi F. de Mello et Paes 1918, p. 51.

1919 Monilia pseudo-bronchialis Castellani 1919, p. 1087.

M. metatropicalis Castellani 1919 , p. 1087, et Chalmers.

1921 Monilia accraensis Macfle et Ingram 1921, p. 274.

2 Torulopsis tonsillse Carnevale-Ricci 1926, p. 46.

1926 \& Blastodendrion kayongosi Mattlet 1926, p. $20>$ (C. W. Dodge 1935, p. 285).

Monilia issavi Mattlet 1926, p. 21.

Blastodendrion irrilans A et B Mattlet 1926, p. 18.

1932 Monilia argentina Vivoli, Avellaneda et Bardessi 1932, p. 239.

1933 Monilia egyptiaca Khouri 1933, p. 7.

1935 Parasaccharomyces irritans (Mattlet 1926) C. W. Dodge 1935, p. 268.

P. talicei C. W. Dodge 1935, p. 269.

Castellania paratropicalis (Castellani 1911) C. W. Dodge 1935, p. 264.

C. accraensis (Macfie et Ingram 1921) C. W. Dodge 1935, p. 264.

C. regyptiaca (Khouri 1933) C. W. Dodge 1935, p. 254.

C. bronchialis (Castellani 1912) C. W. Dodge 1935, p. 254.

C. burgessi (Castellani 1913) C. W. Dodge 1935, p. 255.

C. enterica (Castellani 1912) C. W. Dodge 1935, p. 264.

C. insolita (Castellani 1912) C. W. Dodge 1935, p. 258.

C. lingua-pilosa (Lucet 1901) C. W. Dodge, 1935, p. 260 (synonymie établie d'après les fermentations indiquées par C. W. Dodge).

C. metatropicalis (Castellani et Chalmers 1919) C. W. Dodge 1935, p. 258.

C. pulmonalis (Castellani 1913) C. W. Dodge 1935, p. 255.

Parendomyces perryi (Castellani 1913) C. W. Dodge 1935, p. 243.

Zymonema cruzi (F. de Mello et Paes 1918) C. W. Dodge 1935, p. 176. Syringospora issavi (Mattlet 1926) C. W. Dodge 1935, p. 280.

Mycotoruloides argentina (Vivoli, Avellaneda et Bardessi 1932) C. W.

Dodge 1935, p. 291. 
A cette liste de synonymes, il faut peut-être ajouter Monilia candida car les mycologues nord-américains ont une tendance à nommer ainsi C. tropicalis. Mais quel sera ce $M$. candida? Ce n'est certainement pas le M. candida de Plaut (1885) qui est un albicans. C'est peut-être l'espèce de Bonorden (1851), que Vuillemin (1911) a renommée $M$. bonordeni. Pourtant Berkhout (1923, p. 41-42 et 43) distingue $M$. candida Bon. de $M$. tropicalis Cast, et son $M$. candida (souche Klöcker) fait fermenter le saccharose. D'autre part, ni R. W. Benham (1931) pour son Monilia candida, ni Shrewsbury pour son $M$. candida souche Chapman (?) ne donnent de synonymie et C. W. Dodge est muet à ce sujet. Nous laissons provisoirement de côté l'étude de ce problème et considérons comme tropicalis les M. candida de Benham, Shrewsbury, Martin-Jones-Yao-Lee, etc.

\section{SOUCHES ÉTUDIÉES}

\section{1* Souches nommées}

Monilta tumefaciens alba (Foulerton 1900). - Souche reçue en avril 1930 du Centraalbureau de Baarn. Souche $n^{\circ} 512 \mathrm{~A}$.

Monilia tropicalis (Castellani 1910), - Souche $n^{\prime \prime} 255$ A, provenant de la mycothèque de l'Institut Oswaldo Cruz (Rio de Janeiro).

Souche $n^{\circ} 677$, provenant du Ross Institute de Londres.

Candida insolita (Castellani 1912). - Souche Graziano, envoyée de Sicile par Redaelli. Souche $n^{\circ} 630 \mathrm{~A}$.

Souche Gadetto II, envoyée de Sicile par Redaelli. Souche $n^{*} 631$ A. Candida kefyr (Beijerinck). - Souche $n^{*} 717$ A, reçue en décembre 1931 du Centraalbureau de Baarn.

Souche $513 \mathrm{~A}$, reçue de Baarn en avril 1930.

Candida vulgaris (Bonorden) Berkhout 1923. - Souche reçue du Centraalbureau de Baarn en avril 1930. Souche $518 \mathrm{~A}$.

Monilia krusei. - Souche existant sous ce nom dans la Mycothèque de l'Institut de parasitologie depuis 1927. Souche $n^{\circ} 267 \mathrm{~A}$.

Mycotorula dimorpha Redaelli et Ciferri 1935. - Souche communiquée par Redaelli (Souche Soliman $\mathrm{n}^{*} 3$ ). Souche $n^{*} 578 \mathrm{~B}$.

Mycotorula trimorpha Redaelli et Ciferri 1935. - Souche communiquée par Redaelli (Souche Graxiano 1933). Souche $n^{*} 580$ B.

Mycotorula zeylanoides. - Souche communiquée sous ce nom par Redaelli (souche Carco $\mathrm{n}^{*}$ 4). Souche 579 B. A notre grande surprise cette souche a présenté les caractères biologiques de $C$. tro. picalis.

\section{$2^{*}$ Souches non nommées}

Souche Mallion, crachats, mycose pulmonaire, Hôpital Sidi Abdallah, Ferryville, Tunisie. 21 novembre 1933. Souche $n^{*} 340 \mathrm{~B}$.

Cas Fernando Azevedo, crachats de mycose pulmonaire? Dr C. Mathis, Institut Pasteur de Dakar, 5 mars 1934, Souche $n^{\circ} \$ 82 B$, 
Souche Vastra, perionyxis des mains, cas Ravaut, Rabeau et Guerra, Hòpital St-Louis, Paris, 1934. Souche $n^{\circ} 414 B$.

Sonche Horta (Rio de Janeiro), levure provenant d'un canal dentaire. Souche $n^{\circ} 671 B$.

Souche Rouyer (Institut du radium, Paris), $\mathrm{n}^{\circ} 500 \mathrm{bis}$, levure isolée de la luette chez un cancéreux. Souche $n^{\circ} 80 \gamma 1, B$.

Historique. - Candida tropicalis a été isolé pour la première fois à Ceylan en 1910 par Aldo Castellani, en partant de crachats de malades atteints d'accidents pulmonaires. Ce champignon a été retrouvé très fréquemment dans la suite, comme le prouve sa longue liste de synonymes.

\section{Caractères macroscopiques des cultures}

1. Gélose glycosée à 2 p. 100. - Les caractères macroscopiques des colonies sont assez variables suivant les souches. Le polymorphisme cultural de cette espèce explique done en partie les dénominations variées sous lesquelles elle a été décrite (insolita, dimorpha, trimorpha, etc.) (pl. XVII, fig. 4 et 5 ).

On peut cependant schématiser comme il suit la description des colonies. Elles sont blanches. La culture de 2-5 jours est lisse, mate, arrondie et convexe. Au bout de 15 jours, le centre est devenu membraneux, irrégulier, plissé, entouré d'une auréole crémeuse, cerclée elle-mème d'une couronne de filaments réguliers qui s'enfoncent profondément dans le milieu (pl. XVII, fig. 5).

Si les termes de cette description restent vrais et constants dans l'immense majorité des cas, les proportions respectives du centre membraneux et de l'auréole crémeuse varient considérablement d'une souche à l'autre et, dans la même souche, au cours des repiquages successifs.

Le centre membraneux peut être réduit à un simple point ou plus fréquemment forme un petit disque qu'on peut enlever en entier avec le fil flambé. D'autres fois, il occupe la majeure partie de la surface de la colonie et on a de la peine à apercevoir l'auréole crémeuse, réduite à un simple liseré, quelquefois mème incomplet et situé de préférence à la partie déclive. Chaque souche se présente en général avec une physionomie particulière.

Dans les milieux fortement peptonés, on peut observer des corenium ou mèches qui hérissent la colonie et lui donnent un aspect très spécial (fig. 2, pl. XVII).

En résumé, C. tropicalis est une espèce à la fois crémeuse et 
membraneuse, mais en proportions variables.- La morphologie microseopique va confirmer cette première constatation.

2. Milieu liquide glycosé à 2 p. 100. - Apparition rapide d'un voile muqueux (1), lisse, fin et d'un anneau complet, n'ayant que 1-2 mm. de hauteur. Le voile peut ensuite s'épaissir et devenir légèrement membraneux, par formation de colonies filamenteuses qui lui restent adhérentes. Dépôt abondant.

3. Liquide de Raulin. - Ni voile, ni anneau.

4. Alcool à 3 p. 100. - Développement moyen sous forme de dépôt. Il n'y a pas de voile, mais le liquide se trouble, par suite d'une très légère végétation de surface, insuffisante pour constituer un voile visible.

5. Lait tournesolé. - Pas de changement ou léger virage au bleu. Formation d'un anneau épais. C'est dans les cultures en lait qu'on observe la morphologie microscopique la plus caractéristique.

\section{Morphologie microscopique}

La principale caractéristique de cette espèce est son dimorphisme, d'ailleurs variable suivant les milieux. Ces derniers, quels qu'ils soient, donnent tous une filamentisation très facile, précoce et abondante, comme le montrera la lecture des planches.

Le dimorphisme consiste dans la production, indépendante et successive ou simultanée de deux sortes d'éléments : les uns, qui constituent la zone crémeuse, sont des blastospores, généralement disposées en verticilles du type Mycotoruloides; les autres, qui forment la zone centrale membraneuse, sont des chainettes simples ou ramifiées issues de pseudo-conidies, et revêtant l'aspect Candida de Langeron et Talice.

\section{Caractères biologiques}

Zymogramme. - Positif pour: glycose, lévulose, maltose, saccharose, galactose ; négatif pour : raffinose, lactose.

Auxanogramme des sucres. - Positif pour : glycose, lévulose, maltose, saccharose, galactose ; négatif pour : raffinose, lactose.

Auxanogramme de l'azote. - Positif pour : peptone, asparagine, histidine, glycocolle, tryptophane, sulfate d'ammonium ; négatif pour : urée et nitrate de potassium.

(1) La souche $414 \mathrm{~B}$ ne donne pas de voile net, mais des ilots. Comme les autres caractères sont identiques à ceux du type normal, elle figure dans la thèse de Guerra sous la désignation de pariété européenne. 


\section{LECTURE DES PLANCHES XVII-XX}

1. Aspect Mycotoruloides avec blastospores. - La fig. 3, pl. XVIII (souche $340 \mathrm{~B}$, culture sur lame de 7 jours sur milieu P.C. à $37^{\circ}$ ), montre l'aspect Mycotoruloides avec verticilles réguliers, plus ou moins arrondis, encore simples ou peu composés : il n'y a en ce point, ni pseudo-conidies, ni chainettes. La fig. 4, pl. XVIII représente un autre point de la même lame à un plus fort grossissement : les verticilles sont composés et augmentent en complication. II y a tendance à la formation de courtes chainettes latérales et de quelques chainettes terminales. Ici les blastospores sont ovales et monomorphes; c'est l'aspect qui correspond à la partie crémeuse des colonies, aussi est-il plus fréquent de le rencontrer dans les souches qui possèdent une grande auréole crémeuse.

$2^{\circ}$ Aspect Candida avec chainettes issues de pseudo-conidies. Les fig. 2, pl. XIX et $1, \mathrm{pl}$. XX (souche $267 \mathrm{~A}$, culture sur lame de 15 jours sur gẻlose glycosée à 2 p. 100 à $25^{\circ}$ ), donnent l'aspect vraiment caractéristique de $C$. tropicalis. Cet aspect est d'ailleurs assez difficile à obtenir sur lames : on le rencontre de préférence dans l'intervalle qui sépare deux stries parallèles assez éloignées l'une de l'autre, sur gélose glycosée à 2 p. 100. Les parties externes de cos stries produisent des filaments trop touffus, difficiles à observer et encore plus à photographier.

Sur un filament axial presque vide, dont on ne distingue plus la division en articles, naissent des pseado-conidies volumineuses et allongées, se colorant fortement à leurs deux extrémités. Ces pseudo-conidies forment, par bourgeonnement, de longues chainettes perpendiculaires au filament. Quelques-unes s'allongent même en un filament très finn, qui peut devenir extrêmement long, n'est pas cloisonnẻ et s'enroule plus ou moins à son extrémité (pl. XIX, fig. 2). C'est d'ailleurs un caractère propre à cette espèce de produire de longs filaments à partir d'un élément quelconque : blastospore, pseudo-conidie ou article du pseudo-mycelium. Nous constatons ici un phénomène de germination, analogue à celui que nous avons décrit plus haut. Il va sans dire que c'est cette structure (chainettes de pseudo-conidies et filaments), qui constitue la partie membraneuse des colonies.

Les fig. 1 et 3 , pl. XIX (souche 340 B, culture d'un mois dans le lait tournesolé), montrent la facilité avec laquelle de grosses chainettes, issues de pseudo-conidies, prennent naissance dans le lait. On y voit aussi le grand développement des filaments.

La fig. 2, pl. XVIII (souche $518 \mathrm{~A}$, culture sur lame de 11 jours, a $25^{\circ}$, sur gélose glycosée à 2 p. 100), représente les deux formes de 
pseudo-conidies que nous avons observées : les unes petites, claires, peu colorables, qui ne donnent jamais de chainettes ; les autres plus grandes, très colorables, à cytoplasme condensé, qui donnent naissance aux chainettes caractéristiques.

Enfin la fig. 1, pl. XVII (souche 677 A, culture de 15 jours en tube sur gélose glycosée à 2 p. 100) montre, dans un étalement dans l'encre de Chine, les chaînettes et les denticules d'insertion des pseudoconidies tombées. Comparer avec la figure représentant $C$. brumpti qui donne aussi des chainettes latérales de blastospores, mais qui ne proviennent pas de pseudo-conidies et sont bien plus petites que les éléments de $C$. tropicalis.

$3^{\circ}$ Action de $\mathrm{CO}^{2}$. - Les fig. 3 , pl. XVII et 1 , pl, XVIII représentent (souche $267 \mathrm{~A}$ ) une strie de 24 heures à $37^{\circ}$, sur lame en milieu $\mathrm{PC}$ et atmosphère carbonique. On constate :

a) La précocité et la rapidité de la filamentisation, augmentées par la température élevée et l'action de $\mathrm{CO}^{2}$.

b) La pauvreté en blastospores et la prédominance du pseudomycelium. C'est cet aspect, ainsi que les fourches terminales, qui ont induit en erreur Langeron et Talice et leur ont fait ranger cette souche dans leur genre Geotrichoides. Dans ces figures, les filaments partent d'une épaisse strie de blastospores et il n'y a pas la moindre trace d'arthrospores.

\section{CANDIDA INTERMEDIA (Ciferri et Ashford 1929)}

Blastodendrion intermedium Ciferri et Ashford 1929, p. 91. Langeron et Talice 1932, p. 61, C. W. Dodge 1935, p. 283.

Souche 493 A. Souche originale du $D^{*}$ Bailey Ashford, février 1930.

Historique. - Levure isolée à Porto-Rico, de l'intestin humain, dans un cas de sprue, associée avec Monilia psilosis (Ashford, 1917).

\section{Caractères macroscopiques des cultures}

1. Gélose glycosée à 2 p. 100. - Colonies blanches crémeuses, humides, plissées au centre. Les plis gagnent en général d'emblée toute la surface ; ils sont fins et peu profonds. Cet aspect a été bien représentè par Ciferri et Ashford (1929, pl. II, fig. 2).

Les colonies sont arrondies, avec des bords légèrement irréguliers (pl. XXII, fig. 5).

Filamentisation. - Il est exceptionnel d'observer, dans les colonies supérieures, une couronne de filaments dégagés. 
2. Milien liquide glycosé à 2 p. 100. - Apparition immédiate (en 24-48 heures), d'un anneau et d'un voile muqueux très net. Le liquide se trouble et il se forme au fond un abondant dépòt. Le milieu fermente.

3. Liquide de Raulin. - Ni voile, ni anneau.

4. Alcool à 3 p. 100. - Ni voile, ni anneau ; un dépôt peu abondant.

5. Lait. - Malgré l'assimilation du lactose, le lait tournesolé n'est pas modifié.

\section{Morphologie microscopique}

En étalement dans l'encre de Chine (fig. 2, pl. XXII) d'une culture sur gélose glycosée à 2 p. 100, on trouve de très longues chainettes de blastospores ovales allongêes ; ces chainettes sont assez résistantes. Les corps noirs qu'on aperçoit dans les cellules sont des préeipités fuchsinophiles et non des asques.

La filamentisation est difficile à obtenir ; le milieu $\mathrm{PC}$, pour cette espèce, n'est pas plus favorable que la gélose glycosée à 2 p. 100 ordinaire, La morphologie est très pauvre : les filaments axiaux sont formés d'articles un peu allongés et réguliers, donnant naissance à des rameaux secondaires insérés à angle obtus et présentant l'aspect Mycocandida (fig. 4, pl. XXII).

D'autres fois, on trouve de longs filaments, formés d'articles à peine plus différenciés que de simples blastospores et donnant naissance à des chainettes latérales verticillées (pl. XXII, fig. 3).

Le caractère dominant de cette espèce est la pauvreté morphologique. qui permet de la distinguer très nettement du $C$. tropicalis malgré l'identité de leurs caractères fermentatifs.

\section{Caractères biologiques}

Zymogramme. - Positif pour : glycose, lévulose, maltose, saccharose et galactose ; négatif pour : lactose et raffinose.

Cette espèce produit une forte fermentation des sucres pour lesquels le zymogramme est positif.

Auxanogramme des sucres, - Positif pour : glycose, maltose, galactose, saccharose, lactose ; négatif pour : raffinose.

L'élection du lactose est un caractère très important, qui permet de séparer cette espèce du C. tropicalis. 
Auxanogramme de l'azote. - Positif pour : sulfate d'ammonium (très faiblement assimilé), peptone et asparagine (fortement assimilées) ; l'histidine et le glycocolle ont au début une action inhibitrice, qui se traduit par la formation d'un disque plus clair que le reste du milieu, mais, au bout de 4-6 jours, on voit apparaitre, sur le bord du disque clair, un demi-cercle linéaire d'assimilation positive.

Négatif pour : urée et nitrate de potassium.

CANDIDA PELLICULOSA Redaelli 1925, p. 71, pl. IX, fig. 1-3

Celte espèce a été isolée par Redaelli, en 1925, d'une caverne pulmonaire tuberculeuse chez un homme à Pavie (Italie).

Souche $719 \mathrm{~A}$, reçue du Centraalbureau de Baarn en décembre 1931.

\section{Caractères macroscopiques des cultures}

1. Gélose glycosée à 2 p. 100. - Colonies blanches, crémeuses, humides ou demi-sèches, lisses, arrondies, à bords lisses. La surface peut présenter de fins secteurs un peu plus sombres (pl. XXIII, fig. 6).

Filamentisation. - Tout à fait exceptionnelle dans les tubes.

2. Milieu liquide glycosẻ à 2 p. 100 . - Au $8^{\circ}$ jour, apparait un voile muqueux, lisse, presque sans anneau. Le liquide se trouble et il y a un dépôt abondant au fond du tube.

3. Liquide de Raulin. - $\mathrm{Ni}$ voile, ni anneau.

4. Alcool à 3 p. 100. - Un voile muqueux et un dépôt très abondant.

5. Lait. - Non modifié dans les dẻlais normaux.

\section{Morphologie microscopique}

La filamentisation est extrèmement difficile à obtenir sur lames. A mesure que la souche vieillit la difficulté augmente.

Quand cette espèce filamente, elle prend l'aspect Mycocandida typique (fig. 3, pl. XXIV) avec très longs filaments bien dégagés ot ramifications à angle très ouvert. Les blastospores sont très caduques et il y a d'assez nombreuses pseudo-conidies (fig. 4, pl. XXIII). 


\section{Caractères biologiques}

Zymogramme. - Positif pour : glycose, lévulose, maltose, saccharose, galactose (pour tous, forte fermentation) ; négatif pour : lactose, raffinose.

Auxanogramme des sucres. - Positif pour : glycose, maltose, galactose, saccharose; négatif pour: lactose, raflinose.

Auxanogramme de l'azote. - Positif pour : peptone; négatif pour : asparagine, urée, histidine, glycocolle, sulfate d'ammonium, nitrate de potassium.

Il est assez difficile, avec cette espèce, d'obtenir les réactions avec netteté, c'est pourquoi, dans la thèse de Guerra, elle est donnée comme assimilant le nitrate de potassium.

\section{III. - GROUPE PSEUDO TROPICALIS}

Extrêmement particulier et distinct, bien que ne renfermant jusqu'à présent qu'une espèce, parce que celle-ci est le seul Cahdida connu faisant fermenter le lactose ; aussi, pour obéir à la $3^{\circ}$ loi de Kluyver-Dekker, il ne fait pas fermenter le maltose.

1. Eléments morphologiques. - a) Filamentisation difficile à obtenir et pauvre, prenant des aspects Mycocandida et Mycotoruloides; b) Blastospores allongées, assez grandes, en nombre très variable, arrondies ou ovalaires ; c) Chlamydospores, absentes ; d) Pseudo-conidies, rares.

2. Zymogramme de levures zymato-osidasiques, saccharo-lactasiques, très caractéristique: positif pour glycose, saccharose, lactose, raflinose, négatif pour maltose.

3. Auxanogramme des sucres négatif pour maltose.

4. Auxanogramme de l'azote non caractéristique.

5. Eléments systématiques - Une seule espèce connue: $C$. pseudo tropicalis (Castellani 1910).

\section{CANDIDA PSEUDOTROPICALIS (Castellani 1910)}

1910 Endomyces pseudotropicalis Castellani 1910, p. 236.

1912 Cryptococcus sulfureus Beauverie et Lesieur 1912, p. 996.

1913 Monilia pseudotropicalis Castellani et Chalmers 1913, p. 825.

1925 Candida mortifera Redaelli 1925. 
1928 Cryptococcus kartulisi Castellani 1928, p. 413.

1931 Monilia sulphurea Vuillemin 1931, p. 84.

1932 Mycocandida mortifera (Redaelli 1925) Langeron et Talice 1932, p. 58. C. W. Dodge 1935 , p. 295.

1934 Blastodendrion procerum Zach 1934, p. 685.

1935 Mycoderma sulfureum (Beauverie et Lesieur 1912) C. W. Dodge 1935 , p. 227.

Castellania pseudotropicalis (Castellani 1910) C. W. Dodge 1935, p. 259.

C. karlulisi (Castellani 1928) C. W. Dodge 1935, p. 260.

Pseudomycoderma mazza C. W. Dodge, 1935, p. 237 (Monilia sp. de Mazza et Niño 1927, p. 545).

\section{SOUCHES ÉTUdIÉES \\ 1. Souches nommées}

Monilia pseudolropicalis Castellani et Chalmers 1913. - Souche $\mathrm{n}^{\circ} 3$ de Castellani, Ross Institute de Londres, mars 1931. Sonches 681 A, $767 \mathrm{~B}, 768 \mathrm{~B}$ et var, metapseudotropicalis $784 \mathrm{~B}$.

Candida morlifera Redaelli 1925. - Souche $n^{\circ} 516$ A, reçue du Centraalbureau de Baarn en avril 1930.

Blastodendrion procerum Zach 1934. - Souche $n^{\circ} 589 \mathrm{~B}$ (souche originale de Zach).

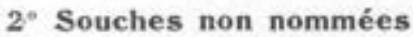

Souche Grigaut, isolée par le $\mathrm{D}^{\mathrm{r}}$ Grigaut des selles d'un malade atteint de sprue, européen ayant séjourné aux Indes. Souche $n^{\circ} 496$ B.

Souches Rouyer (Institut du radium, Paris), isolées de langues noires :

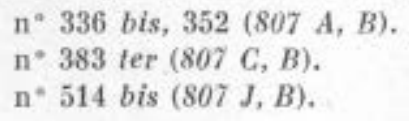

Historique. - Levure isolée par Castellani, en 1910, de plusieurs cas de bronchomycoses à Ceylan. Elle a été retrouvée par divers auteurs, comme l'indique la synonymie, mais elle est généralement méconnue.

\section{Caractères macroscopiques des cultures}

1. Gélose glycosée à 2 p. 100. - Colonies d'un blanc sale, demitransparentes, crémeuses, humides, lisses, très aplaties avec aspect en glacis, arrondies à bords lisses. Quelquefois pourtant elles peuvent présenter un aspect grenu au centre. L'aspect sur gélose glycosée à 2 p. 100 est très caractéristique.

Filamentisation. - On voit rarement des filaments dégagés autour des colonies. 
2. Milieu liquide glycosé à 2 p. 100. - Jamais de voile, ni d’anneau. Un dépót au fond du tube.

3. Liquide de Raulin. - $\mathrm{Ni}$ voile, ni annéau.

4. Aicool à 3 p. 100. - Ni voile, ni anneau. Développement très pauvre.

5. Lait tournesolé. - Vire au rose très rapidement et subit en 24-48 heures, une abondante fermentation, avec dégagement de nombreuses bulles de gaz qui font mousser le liquide lorsqu'on lagite.

\section{Morphologie microscopique}

Cette espèce est caractérisée surtout par des cellules allongées assez grandes. La filamentisation sur lames est difficile à obtenir et échoue quelquefois. Comme toujours, elle est favorisée par l'atmosphère carbonique. Dans une préparation réussie, on trouve des formes Mycocandida et Mycotoruloides.

\section{Caractères biologiques}

Zymogramme. - Très caractéristique.

Positif pour: glycose, lévulose, saccharose, lactose, raffinose (partiellement); négatif pour : maltose.

Auxanogramme des sucres. - Positif pour : glycose, lévulose, saccharose, lactose, raffinose ; négatif pour : maltose.

Auxanogramme de l'azote. - Jamais très net pour cette espèce.

Positif pour: urée, peptone, asparagine, sulfate d'ammonium : négatif pour : nitrate de potassium.

\section{LeCTURE des PLANCHES XIX-XXI}

$1^{\circ}$ Aspect Mycocandida. - La fig. 3, pl. XX (souche $516 \mathrm{~A}=$ Candida mortifera), représente un rameau du type Mycocandida dans une culture sur lame de 3 jours sur milieu PC et en atmosphère carbonique. Les verticilles sont très pauvres, irréguliers; la ramification se fait à angle ouvert, mais non à angle droit comme chez $C$. parakrusei; les blastospores sont allongées, eylindriques et excessivement caduques, ce qui les amène à se rassembler en amas informes.

Dans la même lame, la fig. 4, pl. XIX montre un renflement terminal en tête de spermatozoïde, qui ne peut être considéré comme une 
chlamydospore dont il ne présente aucun des caractères, mais comme une exagération de la tendance qu'ont les filaments et articles de cette espèce à ètre renflés à leurs extrémités.

La fig. 2 , pl. XX montre une lame de la même souche $(516 \mathrm{~A})$, de 10 jours sur milieu $\mathrm{PC}$ et en atmosphère carbonique. C'est toujours l'aspect Mycocandida, avec longs rameaux et verticilles pauvres et espacés ; il n'y a pas de chainettes et les filaments sont terminés par des bouquets de blastospores. Remarquer certains articles du pseudo mycélium, renflés à leurs deux extrémités.

L'aspect Mycotoruloides peut exister dans une lame à côté de points où domine l'aspect Mycocandida. La fig. 4, pl. XX (souche $516 \mathrm{~A}$, culture de 5 jours sur milieu PC en atmosphère carbonique), représente un point où on voit des verticilles composés et étalés bien fournis.

Les fig. 3 et 4, pl. XXI sont prises dans une lame de la souche $681 \mathrm{~A}$ (culture sur milieu PC, laissée pendant 3 jours en atmosphère carbonique, puis ventilée et laissée pendant 3 jours en atmosphère ordinaire). Elles représentent des points analogues à ceux de la fig. 4, pl. XX, mais, sous l'action d'une ventilation abondante, l'extrémité des filaments, qui est la partie la plus jeune et la plus active de la culture, s'est couverte de verticilles très touffus, dus à un bourgeonnement intensif des blastospores terminales. On peut comparer cette figure à la figure 4 , pl. XVIII qui, bien que dans des conditions différentes, montre aussi une active prolifération terminale chez $C$. tropicalis.

\section{IV. - GROUPE GUILLIERMONDI}

Malgré le peu de précision de la diagnose donnée primitivement par l'auteur de l'espèce type, $C$. guilliermondi, ce groupe reste parfaitement reconnaissable, grâce à ses propriétés fermentatives bien spéciales.

1. Eléments morphologiques. - a) Filamentisalion facile; verticilles réguliers et arrondis, avec aspect Mycotorula, ou très réduits du type Mycocandida; b) Blastospores de formes variables; c) Chlamydospores absentes; $d$ ) Pseudo-conidies plus ou moins abondantes.

2. Zymogramme de levures zymato-osidasiques, saccharasiques, trés caractéristique :

Positif pour: glycose, saccharose; négatif pour: maltose et lactose. 
3. Auxanogramme des sucres à peu près superposable au zymogramme.

4. Auxanogramme de l'azote : négatif pour l'urée.

5. Eléments systématiques : deux espèces, C. guilliermondi (Castellani, 1911), C. chalmersi (Castellani 1913).

\section{CANDIDA GUILLIERMONDI (Castellani 1911)}

1911 Endomyces guilliermondi Castellani 1912, p. 1208.

1912 Endomyces negril Castellani 1912, p. 1208.

1913 Monilia guilliermondi Castellani et Chalmers 1913, p. 257.

1913 Monilia lastigi Castellani et Chalmers 1913, p. 828.

1917 Parasaccharomyces ashfordi Anderson 1917, p. 341.

1924 Blastodendrion arzti Ota 1924, p. 232. C. W. Dodge 1935, p. 288.

1926 Monilia muhira Mattlet 1926, p. 23.

1935 Castellania guilliermondi (Castellani 1912) C. W. Dodge, 1935, p. 257.

C. negril (Castellani 1912) C. W. Dodge 1935, p. 253.

C. lustigi (Castellani et Chalners 1913) C. W. Dodge 1935, p. 258.

C. muhira (Mattlet 1926) C. W. Dodge 1935, p. 257.

Syringospora psilosis (Ashford 1917) pro parte, C. W. Dodge 1935, p. 279.

\section{SOUCHES ḱTUDTÉES}

\section{$1^{\circ}$ Souches nommées}

Parasaccharomyces ashfordi Anderson 1917. - Souche $n^{\circ} 1$ A (provenance inconnue).

Monilia guilliermondi Castellani 1911. Souche originale de Castellani (1937), - Souche $n^{\circ} 648 \mathrm{~B}$.

\section{$2^{*}$ Souches non nommées}

Pityrosporum, souche de Macleod et Dowling 1928, donnée par le D' Reiss, de Shanghaï, (juillet 1929). - Souche $373 \mathrm{~A}$.

Souche Pautrier, levure provenant d'un abcès de l'aisselle, Strasbourg, 1933, cas du $D^{\prime}$ Pautrier, - Souche $n^{\circ} 267$ B.

Souche Rivalier, cas Giacomo, conjonctivite, 1934. - Souche $n^{\circ} 397$ B.

Souches Guerra, Hôpital St-Louis, 1934, pyodermite de l'aisselle, cas Gestia. - Souche $n^{\circ} 418 \mathrm{~B}$.

Hôpital St-Louis, 1934, dermite du cuir chevelu, cas Kameneff. Souche $n * 419 B$.

Hôpital St-Louis, 1934. - Souche $420 \mathrm{~B}$.

Souche Abel, cas du $\mathrm{D}^{r}$ Moreau, Bicêtre, envoyé par le $\mathrm{D}^{r} \mathrm{Ch}$, Debray.

Levure de l'urine. - Sonche $n^{\circ} 570 B$. 
Souche Rouyer (Institut du radium, Paris), isolée d'une langue noire, n" 372 bis (Souche 807 B, B).

Historique. - Espèce isolée primitivement de crachats, par Castellani, dans des cas de bronchomycoses, a Ceylan.

\section{Caractères macroscopiques des cultures}

1. Gélose glycosée à 2 p. 100. - Colonies (fig.) blanches, crémeuses, humides, lisses, arrondies à bords nets, non lobulés; elles sont

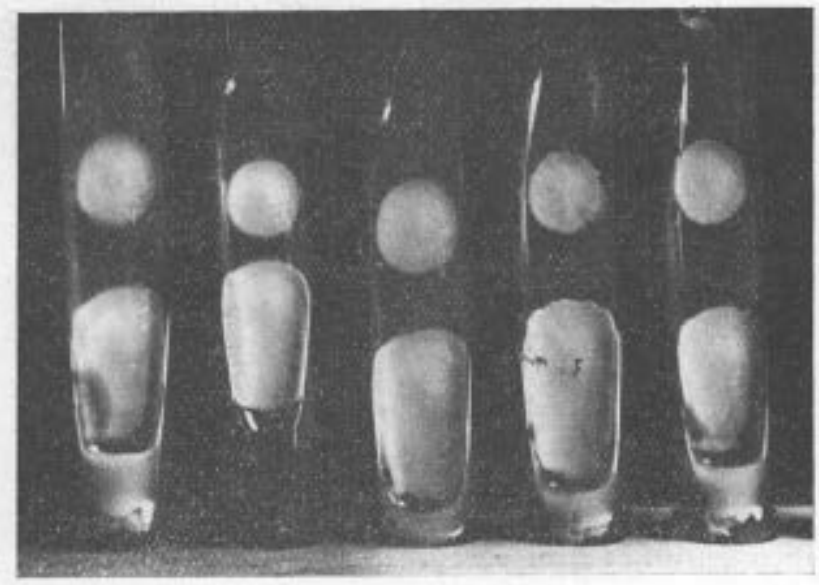

Fid. - Types de colonies de Candida guilliermondi. De gauche à droite, souches : $418 \mathrm{~B}$ (Guerra), $397 \mathrm{~B}$ (Rivalier), $373 \mathrm{~A}$ (Pityrosporum de Macleod et Dowling), 267 B (Pautrier), 1 A (Parasaccharomyces ashfordi).

assez aplaties, plus que celles de $C$. parakrusei; elles peuvent, au bout d'un certain temps, présenter des stries rayonnantes, alternativement blanches et sombres. Contrairement à l'opinion de Kurotehkine (1936), nous n'avons jamais observé aucun plissement, ni aucune irrégularité de surface, même en employant, comme cet auteur, des milieux fortement peptonés.

Filamentisation. - Les colonies supérieures présentent une couronne de filaments assez réguliers, mais courts. Vus à travers la paroi du tube, ils sont assez difficiles à distinguer, a cause de leur faible dimension. L'absence de longues chainettes de grosses blastospores dans les cultures àgées, permet de ne pas confondre 
cette espèce avec $C$. parakrusei qui présente avec elle, dans ses colonies géantes, une grande ressemblance.

2. Milieu liquide glycosé à 2 p. 100 . - A l'étuve à $25^{\circ}$, on voit, dès le $4^{*}$ jour, apparaitre un voile muqueux mince. L'anneau est bas et mince, les parois du tube sont striées de blanc par une pluie de blastospores qui se détachent de l'anneau (anneau pleureur) (chez quelques souches, ce caractère est moins net). Le liquide est trouble.

3. Liquide de Raulin. - Ni voile, ni anneau.

4. Alcool à 3 p. 100. - Ni voile, ni anneau. Développement moyen.

5. Lait. - Aucun changement après 20 jours.

\section{Morphologie microscopique}

La filamentisation est facile à obtenir sur lames en milieu PC et à $25^{-}-27^{\circ}$. Ce qui frappe le plus, dans les préparations ainsi obtenues, c'est la petitesse des blastospores $(2-2 \mu 6$ sur $3 \mu 25-6 \mu)$.

Ces cultures sur lames présentent deux aspects qu'on retrouve en proportions variables dans toutes les souches que nous avons étudiées, quelquefois séparément, quelquefois coexistant sur la même lame.

1. Aspect verticillé, avec glomérules réguliers, arrondis, mais beaucoup plus petits que ceux de C. albicans. C'est d'ailleurs cette apparence qui a induit en erreur Langeron et Talice pour le Pityrosporum, souche Macleod et Dowling, dont ils ont fait un Mycotorula.

2. Chainettes de blastospores allongées, plus ou moins renflées à une de leurs extrémités (aspect stalagmoïde, caractéristique des Blastodendrion pour Langeron et Talice).

\section{Caractères biologiques}

Zymogramme. - Positif pour : glycose, lévulose, saccharose, galactose, raffinose; négatif pour : maltose et lactose.

Avec le galactose et le raffinose, la quantité de gaz peut être faible; elle peut même passer inàperçue avec le procédé de la cloche renversée.

D'ailleurs toutes les souches que nous avons étudiées ne présentent pas la mème puissance fermentative. En général, les fermentations de cette espèce sont meilleures à $25^{\circ}$ qu'à $37^{\circ}$. Le gaz 
n'apparait qu'après quelques jours, aussi, pour avoir des résultats constants et nets, faut-il garder les tubes de fermentation en observation pendant au moins 20 jours.

Auxanogramme des sucres. - Positif pour : glycose, lévulose, saccharose, raffinose; négatif pour : lactose et maltose.

Auxanogramme de l'azote - Positif pour : peptone, asparagine, histidine, glycocolle, tryptophane, sulfate d'ammonium; négatif pour : urée et nitrate de potassium.

\section{LeCtURE dES PLANChES XXIII ET XXIV}

1. Aspect verticille. - Cet aspect est fourni par la souche $\mathrm{n}^{\circ} 373 \mathrm{~A}$, conservée sous le nom de Pityrosporum, souche de Macleod et Dowling, isolée du cuir chevelu. Les fig. 1 et 2, pl. XXIV montrent l'aspect verticillé à deux grossissements différents. On voit les verticilles arrondis, réguliers, et, par endroits, une filamentisation en chaînettes qui donne à l'arbuscule, un aspect échevelé (en haut de la fig. 2, pl. XXIV). Comparer la taille des glomérules à celle des glomérules de C. albicans (fig. 1, pl. XII).

2. Chainettes de blastospores. - La fig. 2, pl. XXIII (souche $418 \mathrm{~B}$ ), montre bien ces longues chainettes de blastospores légèrement stalagmoïdes, divisées irrégulièrement. Remarquer l'absence de verticilles et de pseudo-conidies.

La mème souche a fourni la fig. 5 , pl. XXIII oủ l'on voit des blastospores allongées, des ébauches de verticilles, des blastospores caduques tombées, au milieu desquelles on aperçoit de gros articles vides du pseudo-mycelium et une grosse pseudo-conidie.

\section{CANDIDA CHALMERSI (Castellani 1913)}

1911 Endomyces paratropicalis D Castellani 1911, p. 236.

1913 Endomyces chalmersi Castellani 1913, p. 184.

Monilia chalmersi Castellani et Chalmers, 1913, p. 826.

1935 Castellania chalmersi (Castellani 1913) C. W. Dodge 1935, p. 257.

Historique. - Cette espèce (souche $605 \mathrm{~B}$ ) a été isolée par Castellani, à Ceylan, de erachats dans des cas de bronchomycoses. L'un de nous l'a retrouvée à Paris, à l'Hôpital St-Louis (souche Guerra 605 B) dans un intertrigo interfessier avec prurit anal : nous l'avions d'abord considérée comme une espèce nouvelle et 
nous lui avions donné le nom de Candida lodderi (1), mais nous avons dû reconnaitre dans la suite que ses caractères fermentatifs étaient identiques à ceux de Monilia chalmersi décrit par Castellani en 1911 sous le nom d'Endomyces paratropicalis D, puis, en 1913, sous le nom d'Endomyces chalmersi.

\section{Caractères macroscopiques des cultures}

1. Gélose gìycosée à 2 p. 100. - Colonies (pl. XXIII, fig. 3) blanches, crémeuses, finement plissées, arrondies, à bords finement lobulés. Ces colonies ressemblent à celles de C. aldoi.

Filamentisation. - En couronne autour des colonies supérieures.

2. Milieu liquide glycosé à 2 p. 100. - Il se forme d'abord un anneau, puis, vers le $5^{*}$ jour, un voile épais, bien net, tombant facilement au fond du tube.

La présence d'un anneau et d'un voile très net chez cette espèce, a une grande importance, car c'est le seul caractère macroscopique net qui différencie cette espèce de $C$, aldoi. Ce dernier ne produit ni anneau, ni voile, à aucun moment de son évolution en milieux liquides.

3. Liquide de Raulin. - Ni voile, ni anneau. Dépôt abondant.

4. Alcool à 3 p. 100. - Ni voile, ni anneau. Développement médiocre.

5. Lait. - Non modifié dans les délais normaux.

\section{Morphologie microscopique}

La filamentisation est facile à obtenir sur tous les milieux : elle est du type Mycocandida, à cellules assez grandes et allongées (fig. 4, pl. XXIV). Cette espèce se distingue en outre par la production de nombreuses psendo-conidies (fig. 1, pl. XXIII).

\section{Caractères biologiques}

Zymogramme. - Positif pour : glycose, avec fermentation forte et rapide, saccharose et galactose, action très faible et tardive; négatif pour: maltose, lactose, raffinose.

(1) Dédiée à notre honorée collègue de Delft, Mlle J. Lodder, dont les trìs belles recherches physiologiques sur les levures anascosporées ont été pour nous un guide précieux. 

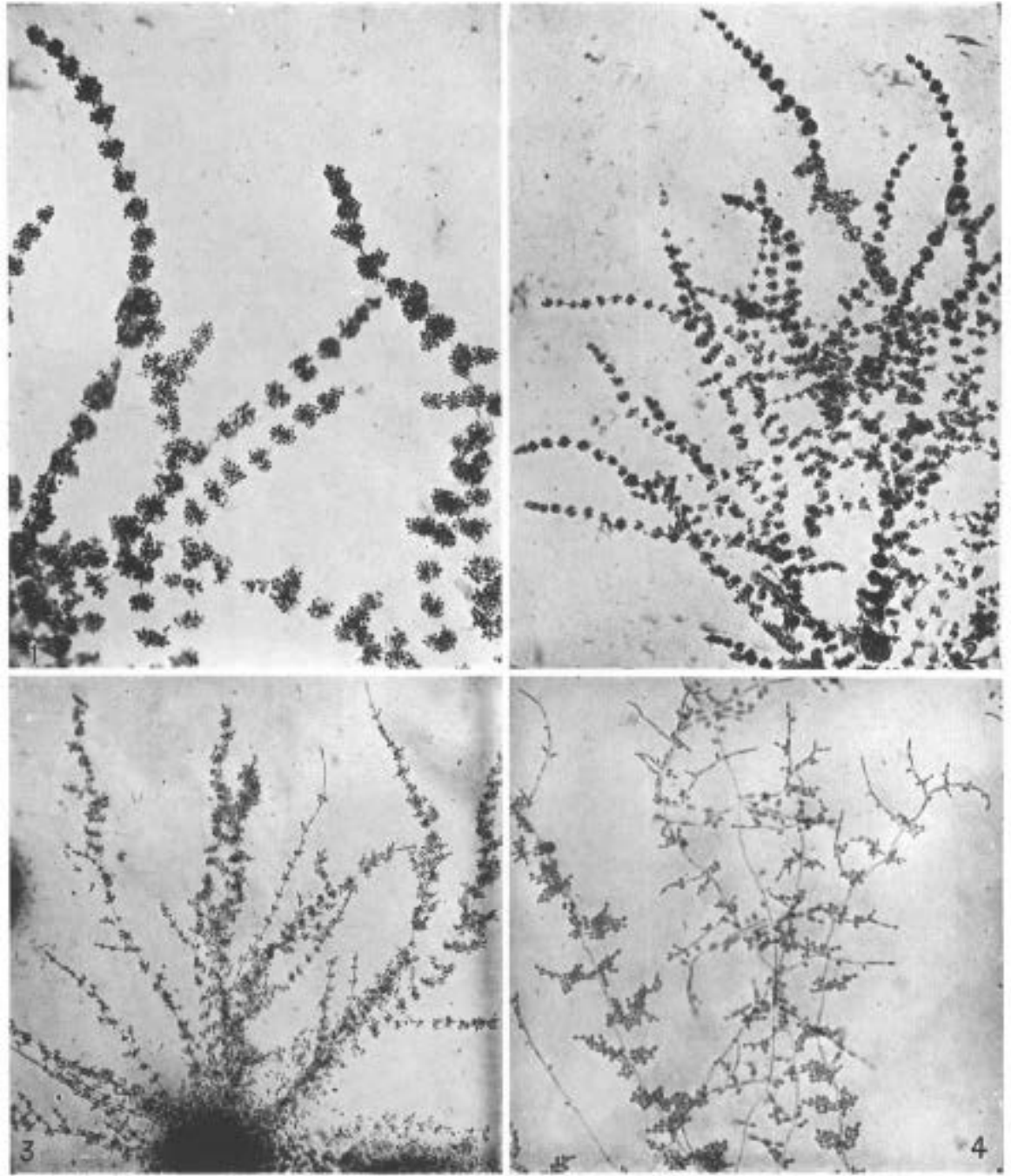

ANNALES DE PARASITOLOGIE

T. XVI, No 5, 1*r Septembre 1938
Planche XIII

(Mémoire Langeron et Guerra)

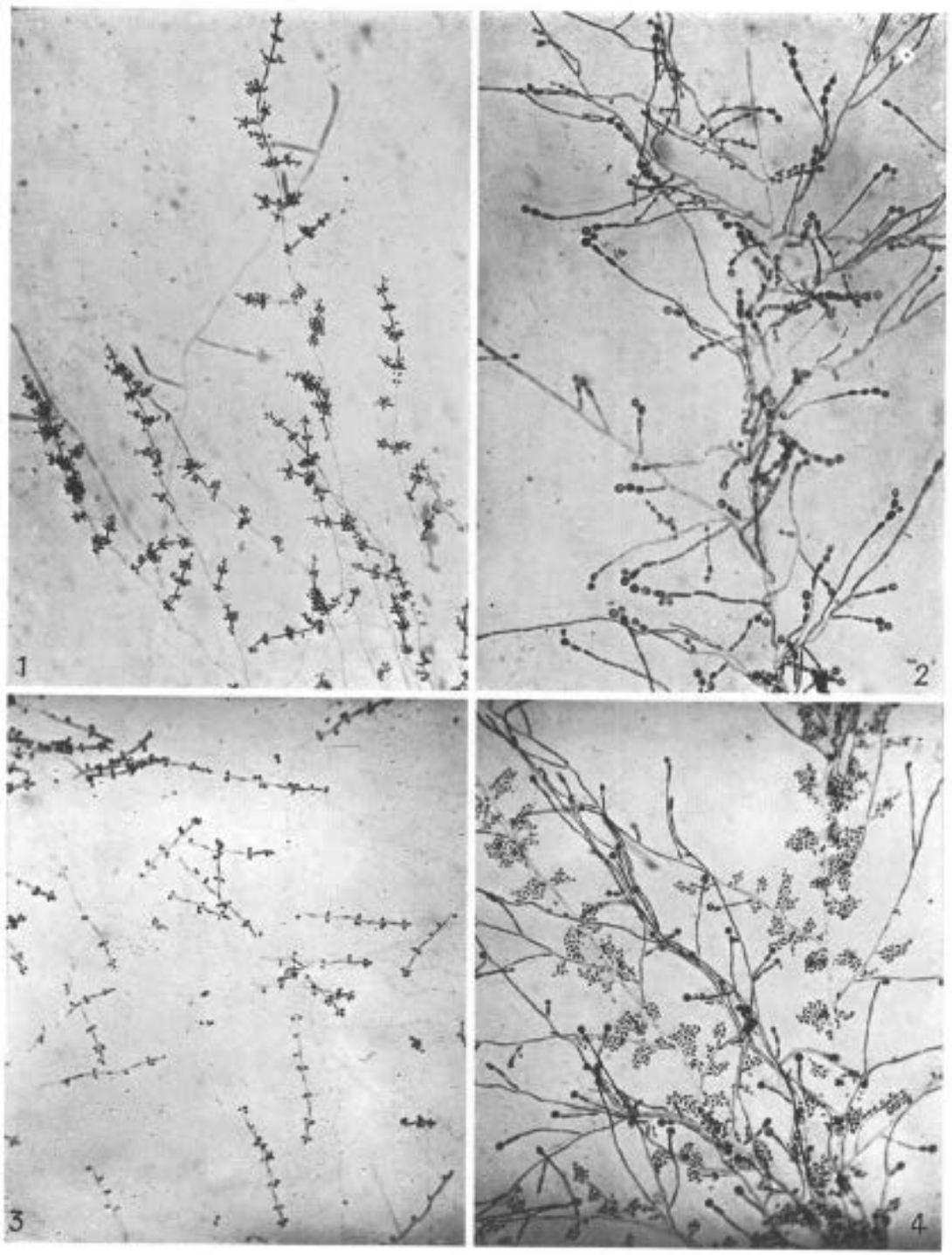



INNALES DE PARASITOLOGIE

I. XVI, No 5, Ier Septembre 1938
Planche XIV

(Mémoire Langeros et. Guema)

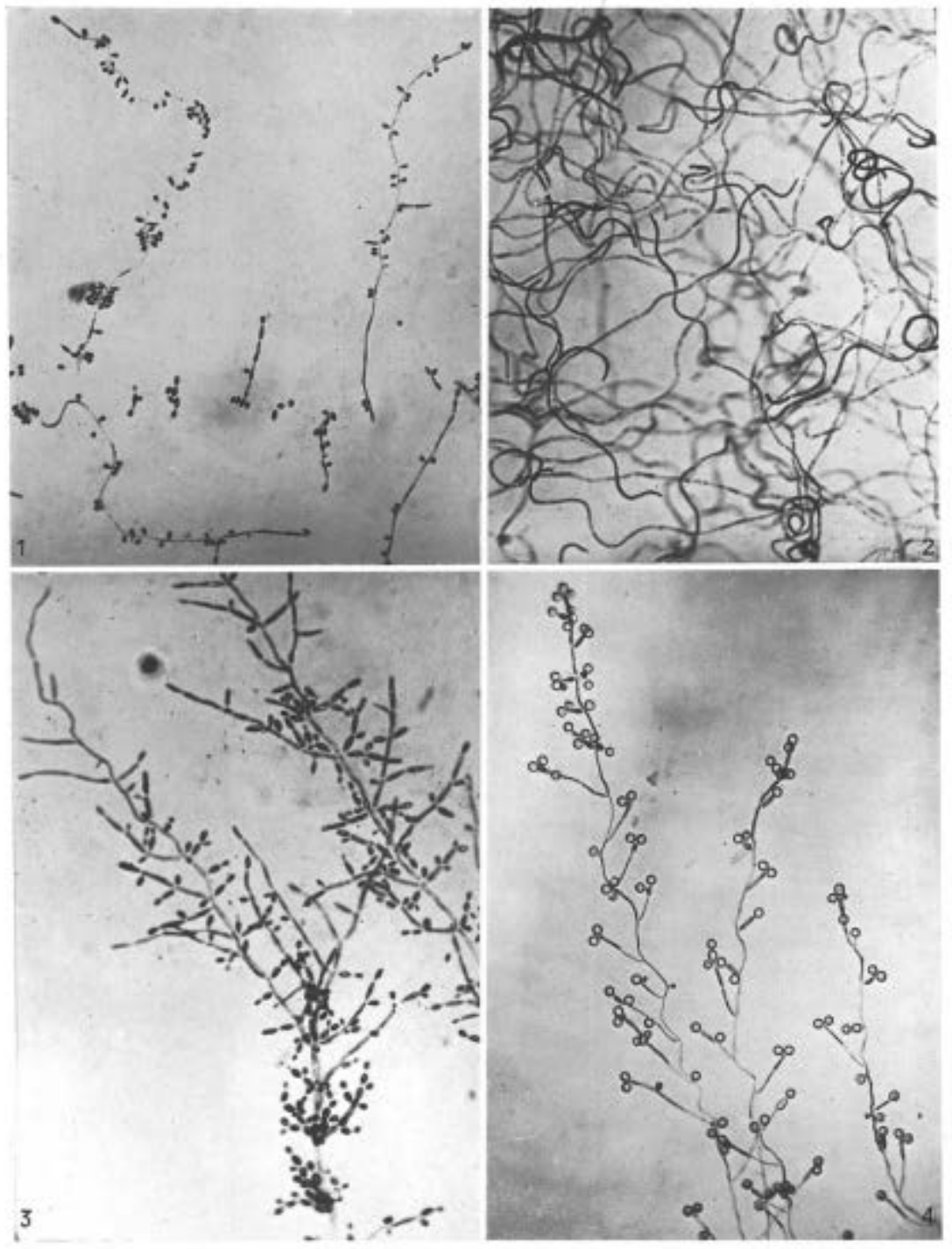





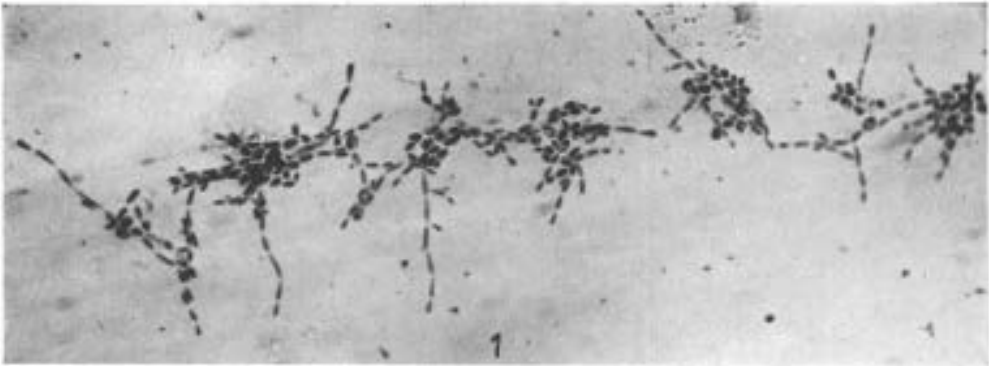

2


Masson et Cie, Editeurs 

ANNALES DE PARASITOLOGIE

T. XVI, No 5, 1er Septembre 1938
Planche XVI

(Mémoire Langeron et Geeria)

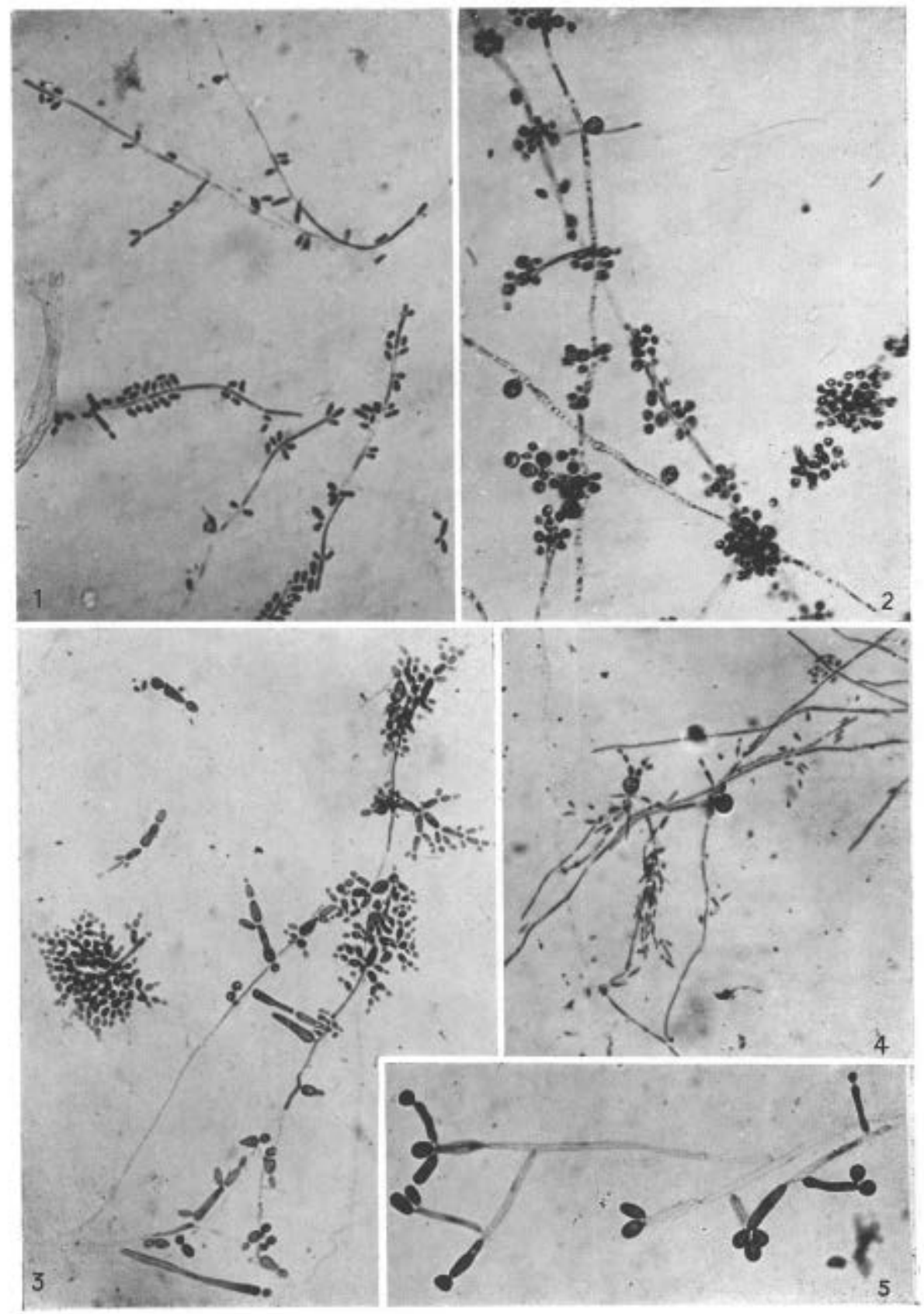




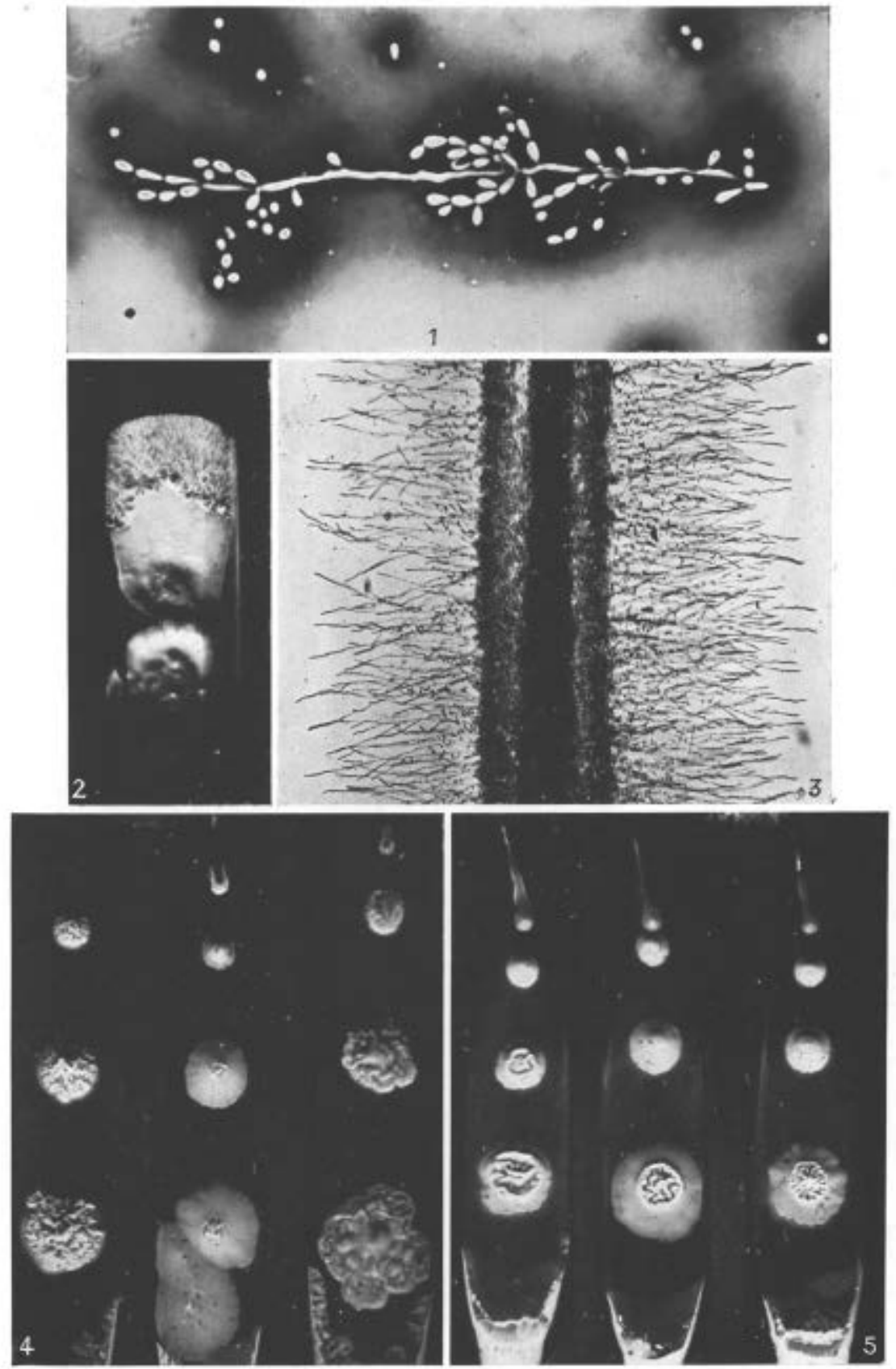

Masson et Cie, Eniteuns 

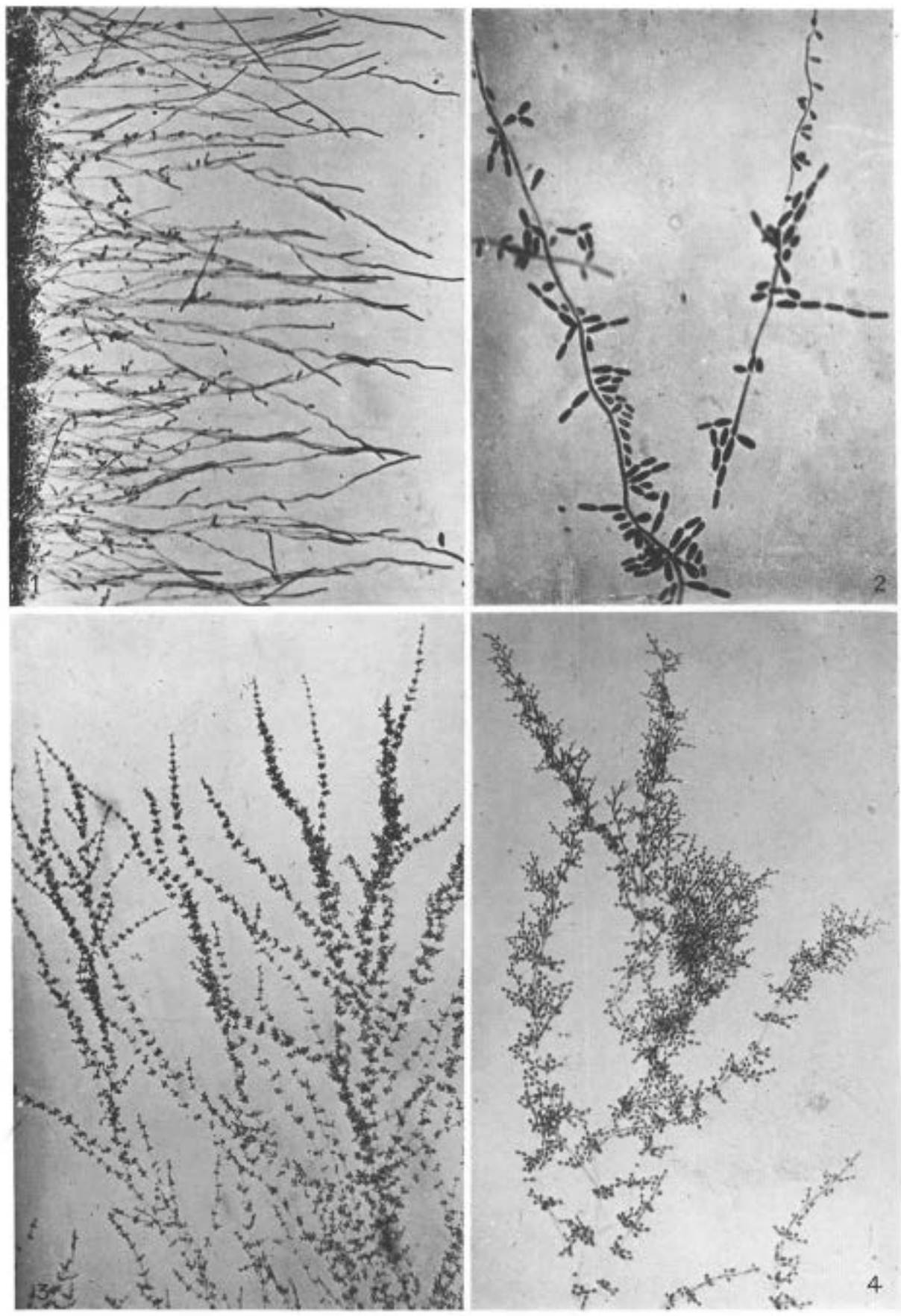


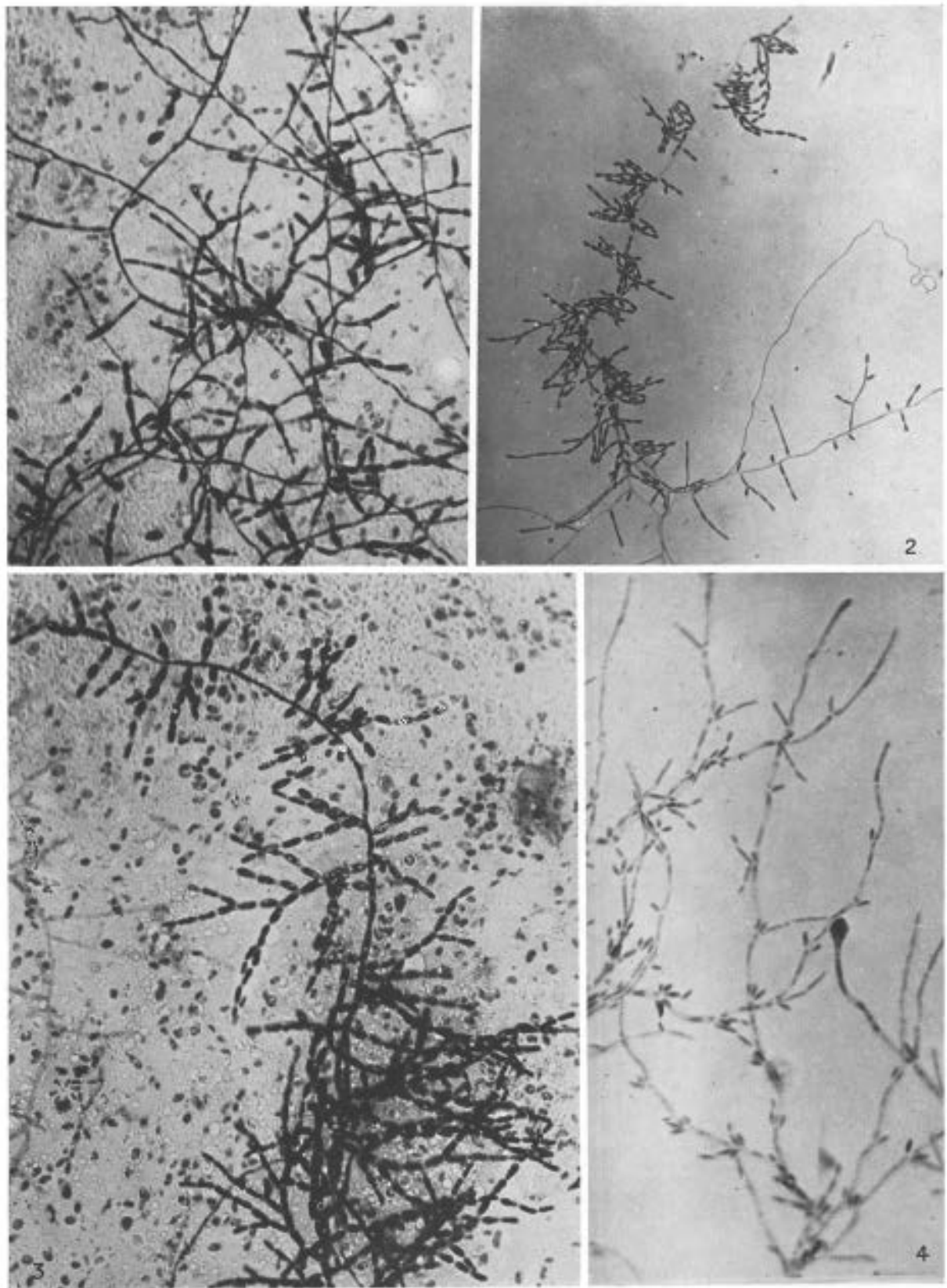

Masson et Cie, Editeuns 



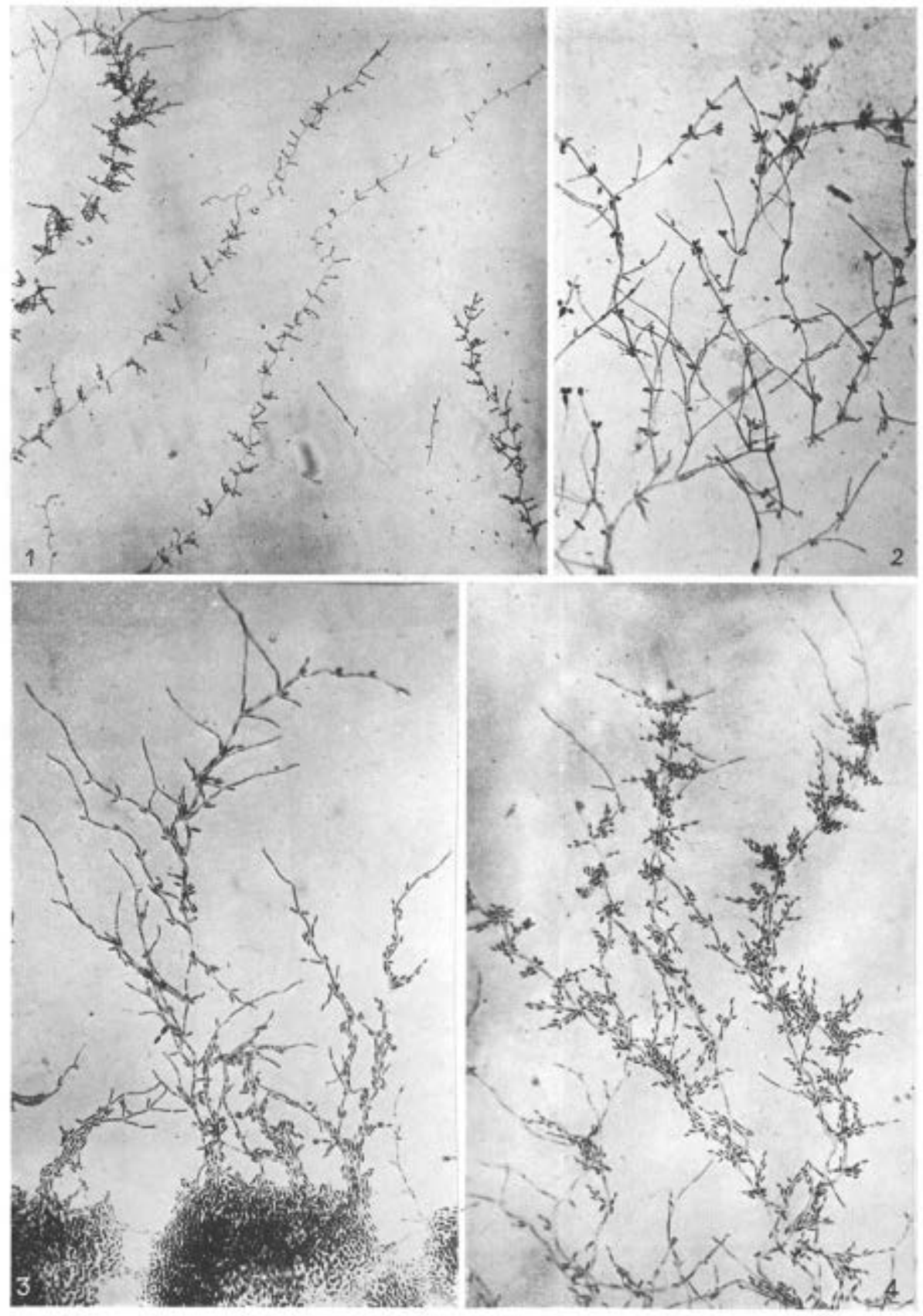




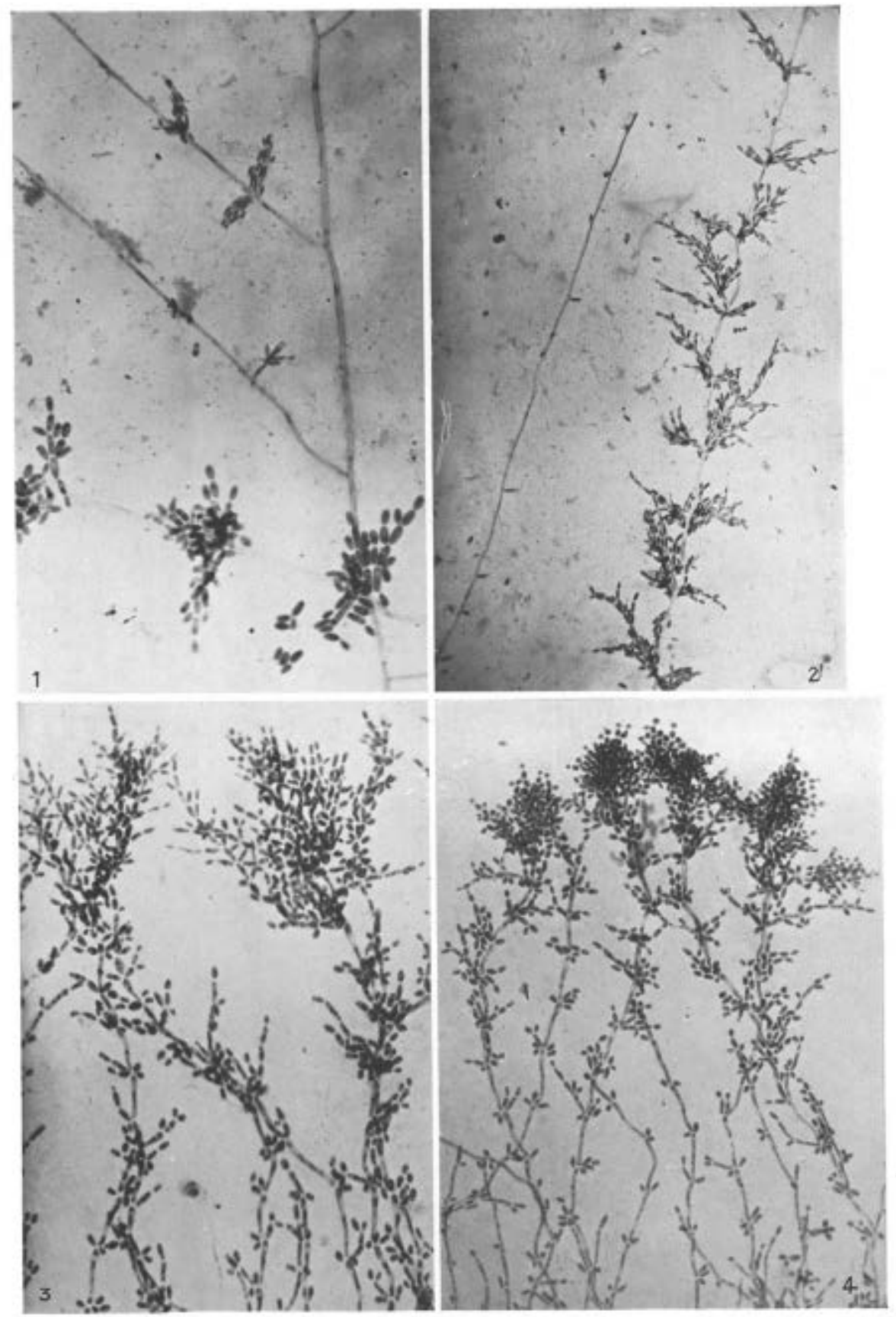

Masson et Cie, Editeurs 

ANNALES DE PARASITOLOGIE

T. XVI, No 5, 1er Septembre 1938
Planche XXII

(Mèmoire LaNgenoN et Guerra)
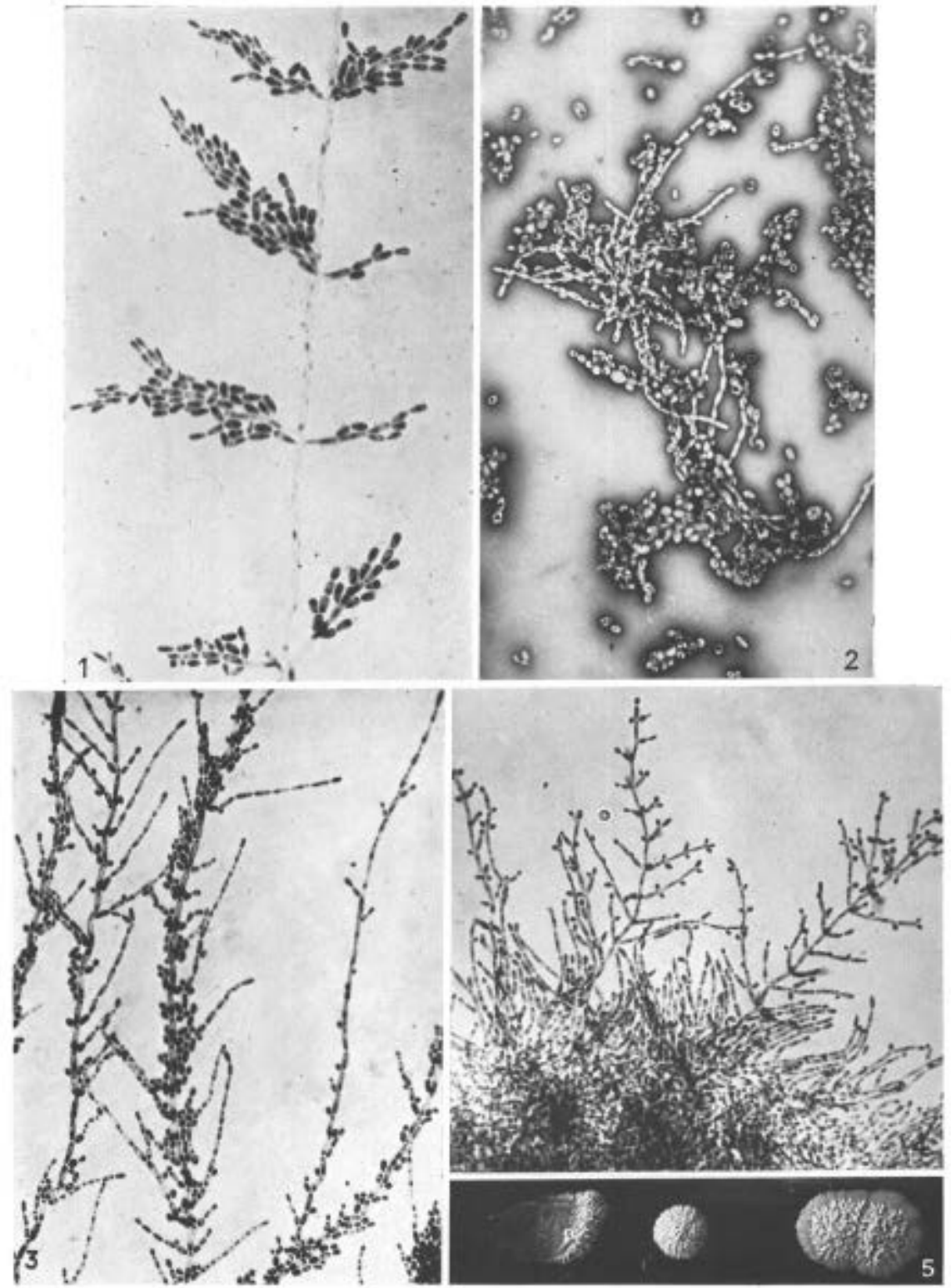








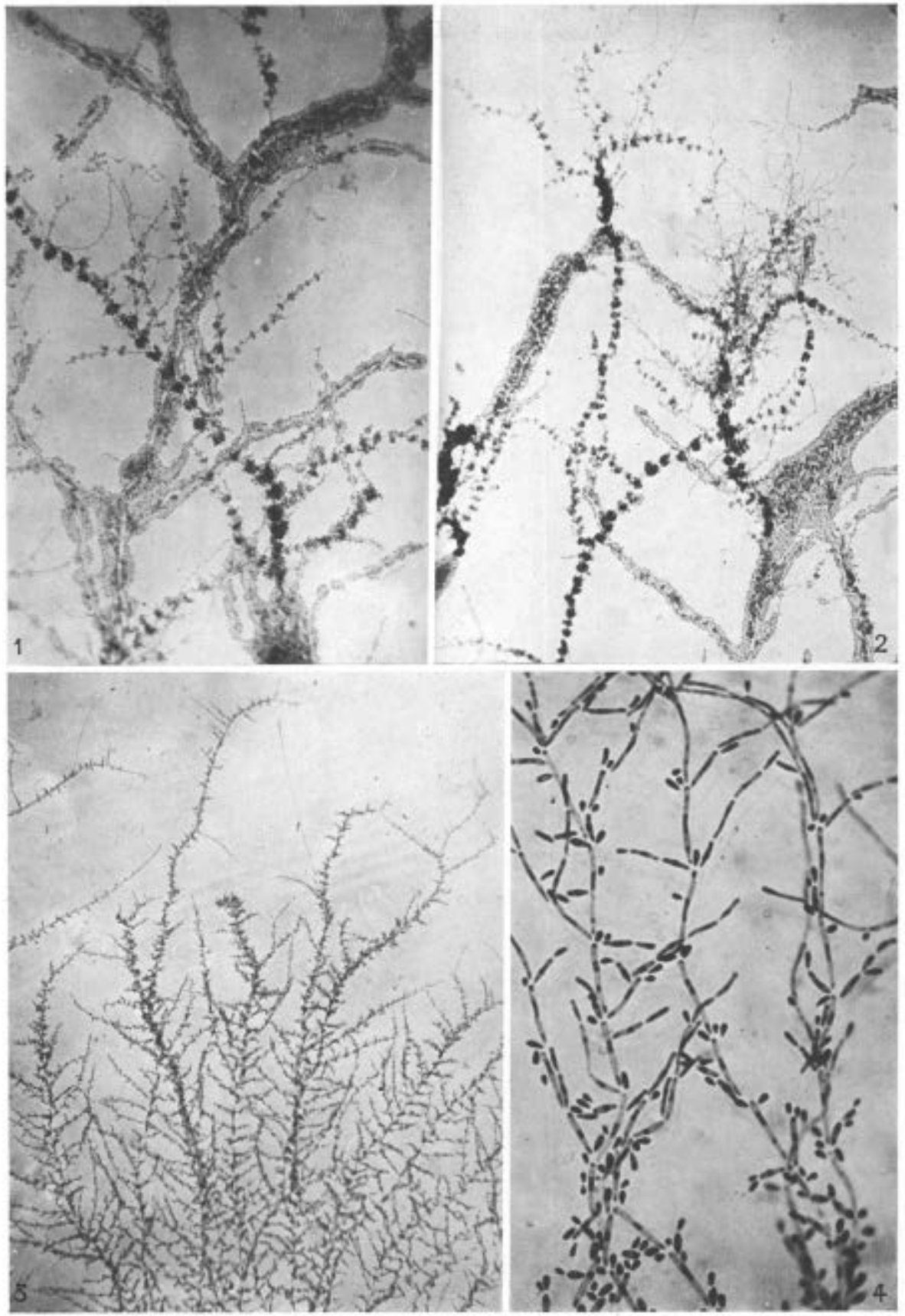


A uxanogramme des sucres. - Positif pour : glycose, maltose, gal ictose, saccharose ; négatif pour : lactose, raflinose.

Auxar ogramme de l'azote. - Positif pour : peptone, asparagine, histidin, glycocolle, sulfate d'ammonium; négatif pour: urée, nitrate le potassium.

(à suivre).

\section{EXPLICATION DES PLANCHES XII-XXIV (1)}

\section{Plaxche XII \\ Candida albicans}

Fic. 1 et 2, - Appareil sporifère vertieillé du type Mycotorula. Souche Guerra 448 B. Hôpital St-Louis, perionyxis de la main. Gélose glycosée à 2 p. 100. Fig. 1, X 200; fig. 2, $\times 100$.

F16. 3. - Appareil sporifère verticillé du type Mycotoruloides. Souche Cattiau 160 B. Hôpital St-Louis. (Souche Ravaut), Gélose glyeozée à 2 p. $100, \times 100$.

FiG. 4. - Appareil sporifère verticillé. Souche 417 A, Hòpital St-Louis, collection R. Sabouraud, culture de 8 jours sur gélose glycosée à 2 p. $100 . \times 200$.

\section{PLasche XIII}

\section{Candida albicans}

Fis. 1. - Filamentisation et appareil sporifère vertieillé du type Mycolorula. Souche 647 B (Monilia pinoyi), souche de Castellani. Culture de 8 jours sur gélose P.C. $\times 200$.

F16. 2, - Début de la formation des protochlamydospores et des ehlamydospores; fllaments moniliformes qui donneront les bouquets de chlamydospores Culture sur gülose P.C. Souche 403 A, Hopital St-Louis, collection R. Sabouraud. $\times 200$.

Fı, 3. - Début de la formation de l'appareil sporifère verticillé. Souehe Guerra 448 B, Hôpital St-Louis, perionyxis de la main. Gélose glycosée à 2 p. 100. $\times 200$.

FiG. 4. - Jeunes chlamydospores portées par leurs protochlamydospores, D'autres filaments sont chargés de vertieilles de blastospores déjà trís évolués. Souche Guerra $517 \mathrm{~B}$, Hopital St-Louis, grand intertrigo avee levurides. Gélose glyensée à 2 p. $100 . \times 200$.

\section{PLANCHE XIV}

\section{Candida albicans}

Fı́, 1. - Apparition des pseudo-conidies. Souche $403 \mathrm{~A}$, Hôpital St-Louis, collection R. Sabouraud, Gélose glyeosée à 2 p. 100 . $\times 200$.

Fic. 2, - Aetion de $\mathrm{CO}^{2}$, hypertrophie désordonnće de la filamentisation. Souche Cattiau 160 B, Hôpital St-Louis (Souche Ravaut). Gélose P.C. en atmosphère earbonique, $\times 400$.

(1) Toutes ces figures (sauf celles de colonies gèantes en tuhes) sont des microphotographies prises sur nos cultures sur lames gélosées.

Les grossissements sont approximatifs.

Ansales de Parasitologie, T. XVI, $\mathrm{N}^{*} 5 .-1^{\text {er }}$ septembre 1938. 
F16, 3. - Filamentisation du type Mycotoruloides avee grandes blastospores et pseudoconidies. (Monilia pinoyi), Souche $682 \mathrm{~A}$, Ross Institute de Londres. $\times 400$.

F1G. 4. - Bouquets typiques de ehlamydospores. Souche Novoty, Hopital St-Louis (Souche Guerra). Culture de 11 jours sur gélose P.C. $\times 200$.

\section{Plancie XV}

Candida albicans. Action modificatrice du milieu

Fic. 1, - Chainettes de blastospores allongćes (aspeet Candida). Souche $561 \mathrm{~B}=$ Souche Talice et Mackinnon 477 (Monilia inexorabilis). Culture de 15 jours. gélose P.C. $\times 400$.

Fica, 2. - Chainettes de blastospores (aspect Candida). Culture de 3 jours sur gélose P.C. Souche 417 A, Hôpital St-Louis, collection R. Sabouraud, $\times 400$.

F16. 3. - Souche 682 A (Monilia pinogi, du Ross Institute de Londres). Bourgeonnement des pseudoconidies après contact de la lame gélosée avee le liquide du fond du tube Borrel. $\times 400$.

F16. 4. - Aspect Blastodendrion à verticilles dressés, appliqués sur l'axe : remarquer les renflements du filament axial. Culture de 6 jours a $37^{\circ}$ sur gélose P.C. Souche 417 A, Hôpital St-Louis, collection R. Sabouraud. $\times 200$.

Fui. 5. - Aspect Mycotorula avec verticilles réguliers et globuleux. Souche 417 A. Hôpital St-Louis, collection R. Sabouraud. Culture de 8 jours sur gélose glycosée à 2 p. 100 en atmosphère earbonique. $\times 100$.

\section{Planche XVI}

\section{Candida albicans}

FıG, 1. - Manchons de pseudoconidies et germination sur place des blastospores d'une colonie membraneuse. Souche $563 \mathrm{~B}=$ Souche Talice et Mackinnon 471 (Monilia alvarezsotoi). Culture de 25 jours sur gélose P.C. $\times 400$.

Fic. 2, - Action de CO2. Souche $417 \mathrm{~A}$, Hopital St-Louis, collection R. Sabouraud. Verticilles globuleux de blastospores arrondies et grosses chlamydospores sessiles (sans protochlamydospores). Culture de 8 jours sur gélose glycosée à 2 p. 100 en atmosphère carbonique. $\times 400$.

Fi6. 3. - Germination des pseudoconidies après dessiceation à $37^{\circ}$ puis retrem page dans l'eau peptonée, glyeosée à 4 p. 100 , d'une eulture de 15 jours sur gélose P.C. Souche 563 B = Souche Talice et Mackinnon 471 (Monilia alvare:sotoì). $\times 400$.

Fu. 4. - Bourgeonnement de chlamydospores mûres et acido-résistantes, avec formation de chainettes de blastospores. Culture de 15 jours sur gélose P.C. Souche $561 \mathrm{~B}=$ Souche Talice et Mackinnon 477 (Monilia inexorabilis), $\times 400$.

Fia. 5. - Souche 682 A, provenant du Ross Institute de Londres (Monilia pinoyi). Protochlamydospores et jeunes chlamydospores. $\times 400$.

\section{Planche XVII}

\section{Candida tropicalis}

F16. 1. - Etalement dans Pencre de Chine d'une culture de 15 jours en tube sur gélose glycosée à 2 p. 100 de la souche $677 \mathrm{~A}$, du Ross Institute de Londres. Chainettes de blastospores et dentieules d'insertion des pseudoconidies dont quelques-unes sont encore en place. $\times 400$.

Fi6. 2. - Colonies géantes de la souche $677 \mathrm{~A}$, du Ross Institute de Londres. Culture de deux mois sur gélose peptonée à 10 p. 100 et glycosíe à 2 p. 100 . Remarquer les mèches qui hérissent ces colonies. 
Fic. 3. - Action de $\mathrm{CO}^{2}$. Souche 267 A. Strie d'ensemencement de 24 h. a $37^{\prime \prime}$ sur lame gélosée (gélose P.C.) en atmosphère carbonique. Accélération de la filamentisation, prédominance du pseudomycelium, rareté des blastospores. $\times 100$.

F16. 4. - Colonies géantes de C. tropicalis sur gélose glyeosée à 2 p. 100 . De gauche à droite, souches : $717 \mathrm{~A}$ (C. kefyr), $677 \mathrm{~A}$ et $513 \mathrm{~A}$ (C. kefyr).

Fı́. 5. - Colonies géantes de C. tropicalis sur gélose glycosée à 2 p. 100. De gauche à droite, souches: $579 \mathrm{~B}$ (M. zeylanoides), $578 \mathrm{~B}$ (M. dimorpha) et 580 B (M. trimorpha).

\section{PL.Axche XVIII \\ Candida tropicalis}

F1G. 1. - Portion plus grossie de la fig. 3, pl, XVII. On voit encore mieux les fourches terminales des filaments et la rareté des blastospores. $\times 200$.

Fuc. 2, - Pseudoconidies de deux types : les unes petites, elaires, peu colorables, ne donnant jamais de chainettes; les autres grandes, très colorables, à cytoplasme condensé, donnant des chainettes. Culture sur lame de 11 jours a $25^{\circ}$ sur gélose glycosée à 2 p. $100 . \times 400$.

Fi6. 3. - Aspect Mỵcotoruloides avec verticilles réguliers, composés, étalés. Souche 340 B (Tunisie), culture sur lame de 7 jours à $37^{\circ}$ sur milieu P.C. $\times 100$.

Fit. 4, - Même souche que pour la fig. 3 et autre portion de la même lame : aspect correspondant à l'auréole crémeuse des colonies géantes en tubes. Vertieilles composés et touffus, formés de blastospores ovales, monomorphes, en chainettes latérales et terminales, $\times 200$.

\section{Planche XIX}

\section{Candida tropicalis et $C$. pseudotropicalis}

Fı́, 1 et 3. - Culture d'un mois, dans le lait tournesolé, de la souche $340 \mathrm{~B}$ (Tunisie). Formation de longues et volumineuses chalnettes aux dépens de pseudoconidies pleurogènes. Filamentisation très développée. $\times 400$.

Fi6. 2, - Culture de 15 jours sur lame gélosée (gélose glycosée à 2 p, 100) de la souche $267 \mathrm{~A}$. Aspect très caractéristique de $C$. tropicalis, avec longues chainettes issues de pseudoconidies. A droite, très long filament grêle, non cloisonné, enroulé à son extrémité. $\times 150$.

F16, 4. - C. pseudotropicalis, souche 516 A (C. mortifera) : aspect Mycocandida; gros renflement terminal. Culture sur lame de 3 jours sur gélose P.C. en atmosphére carbohique, $\times 400$.

\section{Planche XX}

\section{Candida tropicalis et $C$. pseudotropicalis}

F16. 1. - Aspect caractéristique de C. tropicalis. Mème lame que pour la fig. 2 , pl. XIX (en haut à gauche, filament représenté par cette figure). Filaments chez lesquels les chainettes issues des pseudoconidies sont moins allongées et surtout moins touffues. $\times 150$.

Fıt. 2. - Même souche $(516 \mathrm{~A})$ que pour la fig. 4 , pl. XIX. Culture de 10 jours sur lame gélosée (milieu P.C.) en atmosphère carbonique (C. pseudotropicalis). $\times 200$.

Fıc. 3. - Aspect Mycocandida de la mème souche $(516 \mathrm{~A})$ que pour les flg. 4 , pl. XIX et 2, pl. XX. Culture sur lame de 3 jours (milleu gẻlosé P. C.) en atmosphère carbonique. Verticilles pauvres, irréguliers, ramification à angle ouvert, blastospores rares, allongées, cylindriques, très eaduques, $\times 200$.

F16. 4. - Aspect Mycoloraloides de la mème souche (516 A) que pour les deux figures précédentes. Culture de 5 jours sur lame (milieu P.C.) en atmosphère carbonique. $\times 200$. 


\section{PLANCHE XXI \\ Candida pseudotropicalis et $C$. triadis}

Fic. 1. - C. triadis, souche 587 A (collection Guilliermond). Culture de 5 jours sur lame (milieu de Gorodkova). Coexistence, sur un même rameau, de blastospores de deux types : normales et baculiformes. $\times 400$.

Fi6. 2, - C. triadis, souche 587 A (collection Guilliermond). Aspect Mycotoruloides (vertícilles composés, irréguliers, étalés). $\times 200$.

Fıc. 3 et 4. - C. pseudotropicalis, souehe $681 \mathrm{~A}$. Culture sur lame (milieu P. C. en atmosphère carbonique pendant 3 jours et en atmosphère ordinaire pendant 3 jours. L'aération a produit des verticilles terminaux trés touffus, dus à un bourgeonnement intense. (Fig. 3, $\times 400 ;$ fig. $4, \times 350$ ).

\section{PLaxche XXII}

\section{Candida triadis et $C$. intermedia}

F16. 1. - C. triadis. Souche 587 A (collection Guilliermond). Aspect Mycotoruloides. Culture sur lame de 5 jours à $25^{\circ}$ sur millieu de Gorodlcova en atmosphère carbonique. $\times 400$.

Fic. 2, - C. intermedia. Souche $493 \mathrm{~A}$, souche originale d'Ashford. Etalement dans l'encre de Chine d'une culture géante sur gélose glycosée à 2 p. 100 . Longues et solides chainettes de blastospores ovales, allongées, $\times 200$.

Fit. 3 et 4, - C. intermedia. Aspect Mycocandida, surtout typique dans in fig. 4. Culture sur lame sur gélose glycosée à 2 p. 100 . Remarquer la pauvreté morphologique de cette espèce, $\times 400$.

Fıб. 5. - C. intermedia, colonies géantes sur gélose glycosée à 2 p. 100.

\section{PLAXChE XXIII}

Candida pelliculosa, C. guilliermondi, C. chalmersi

Fic, 1. - C. chalmersi. Souche 605 B, culture sur lame sur milieu P.C. Filaments portant surtout des pseudoconidies. $\times 500$.

Fin. 2, - C. guilliermondi. Souche Gestia 418 B. Culture sur lame de 4 jours sur milieu P.C. Longues chainettes de blastospores un peu stalagmoides : ni verticilles, ni pseudoconidies. $\times 200$.

F16. 3, - C. chalmersi. Souche 605 B. Colonies géantes plissées et lobulées sur gélose glycusée à 2 p. 100 .

Fı, 4. - C. pelliculosa. Souche 719 A. Aspect Mycocandida. Blastospores très caduques, nombreuses pseudoconidies. $\times 400$.

Fı. 5. - C. guilliermondi. Souche Gestia $618 \mathrm{~B}$. Culture sur lame de 5 jours sur milieu P.C. Pseudoconidies et blastospores très eaduques. $\times 400$.

Fu. 6. - C. pelliculosa. Souche $719 \mathrm{~A}$. Colonies géantes sur gélose glycosće à 2 p. 100.

\section{Plasche XXIV}

\section{Candida guilliermondi, C. pelliculosa, C. chalmersi}

Fic. 1 et 2. - C. guilliermondi. Souche 373 A (Pityrosporum de Macleod et Dowling). Aspect Mgcoforula: vertieilles réguliers, arrondis. Trainces de blastospores eaduques. En haut de la fig. 2, aspect échevelé dû à une filamentisation en chainettes. Fig. $1, \times 200 ;$ fig. 2 , $\times 150$.

Fic. 3, - C. pelliculosa. Souche 719 A. Aspect Mycocandida typique. Culture sur lames, milieu P.C. $\times 160$.

Fie, 4, - C. chalmersi. Souche 605 B. Filamentisation du type Myeocandida, à cellules grandes et allongées, Blastospores et pseudoconidies. Verticilles pauvres. $\times 500$, 